\title{
Los derechos de autor de los profesionales de la prensa escrita en el ámbito de las nuevas tecnologías en Chile
}

\author{
Copyrights of the news media professionals in the field of new technologies in Chile
}

\author{
Manuel Bernet Páez \\ Universidad de los Andes, Chile
}

Alfredo Sierra Herrero

Universidad de los Andes, Chile

\begin{abstract}
RESUMEN El propósito de este estudio es determinar de qué derechos de autor gozan los profesionales de la prensa escrita en Chile respecto de sus obras creadas inicialmente para un medio impreso, las cuales posteriormente son explotadas a través de nuevos formatos digitales. Esta cuestión no se encuentra resuelta expresamente por la Ley 17.336 de 1970, la que por su data no consideró las actuales formas de aprovechamiento tecnológico, como las ediciones en línea. No obstante, en esta investigación proponemos como tesis que ciertas utilizaciones del empresario periodístico sobre las obras de sus trabajadores en el entorno digital son legalmente admisibles, puesto que ha operado entre ambos una cesión tácita de derechos. En contraste, respecto de los profesionales independientes, sus obras solo podrán ser utilizadas por el titular de un medio de prensa en un ambiente digital si cuenta con una cesión o autorización expresa del autor.
\end{abstract}

PALABRAS CLAVE Derecho de autor, nuevas tecnologías, derecho laboral, prensa escrita.

ABSTRACT This articles aims to determine what copyrights corresponds to the press professionals in Chile and their written publications, initially created for a printed media but then exploited through new digital formats. This issue is not expressly resolved by Law 17.336, since as it was published in 1970 , it did not considered the current forms of technological exploitation, such as online editions. However, we propose as research thesis that certain uses of the news media regarding the publications of their workers in a digital environment are legally admissible, since it has operated between both a tacit transfer of rights. On the other hand, with respect to independent professionals, their 
publications may only be used by the owner of a news media in the digital environment if they obtain a transfer of rights or express authorization from the author.

KEYWORDS Copyright law, new technologies, labor law, written press.

\section{Introducción}

El motivo de esta investigación es determinar de qué derechos de autor disponen los profesionales de la prensa escrita, tanto dependientes como independientes, respecto de sus creaciones en el campo de las nuevas tecnologías. ${ }^{1}$ Lo anterior resulta del todo relevante, puesto que con el devenir de las tecnologías digitales los editores han empezado a explotar comercialmente sus obras - primitivamente publicadas en papel, como el periódico- a través de otros formatos, como las ediciones electrónicas o las bases de datos, sin obtener el consentimiento ni remunerar a los autores de los reportajes o de las fotografías que integraban dichas publicaciones periódicas (D’Agostino, 2008: 38).

Frente al advenimiento de esta nueva realidad, cabe responder si nuestro derecho se hace cargo de la problemática, y si resulta conveniente seguir de cerca las respuestas que al efecto se han dado en otras jurisdicciones. En este sentido, el artículo 24, letra c) de la Ley 17.336 reglamenta de manera particular los derechos de autor de los profesionales de la prensa escrita de las publicaciones periódicas, norma que fue promulgada en 1970 y que por su evidente contexto histórico resulta alejada de los recientes medios de explotación digital.

Por consiguiente, en este trabajo nos haremos cargo de la dificultad de interpretar dicha norma ante nuevos hechos. Nuestro objetivo es entregar una propuesta hermenéutica que sea ajustada a los intereses que pretende cautelar, para lo cual distinguiremos entre la situación jurídica del profesional de la prensa trabajador con respecto al independiente o freelance. Ahora bien, aunque se trata de un análisis limitado a la materia descrita, entendemos que algunos de argumentos que se expresarán para justificar una cesión tácita de derechos del trabajador a favor de su empleador puede servir como un primer paso dogmático para construir una teoría general sobre la transferencia de los derechos de autor en el marco de una relación laboral, con independencia del sector económico en que se presente.

Para llevar a cabo los objetivos indicados, inicialmente examinaremos el estado de la cuestión en el derecho comparado, teniendo a la vista en particular el derecho estadounidense - verdadera cuna de la economía digital- y el derecho francés, por ser especialmente representativo de la familia del droit d'auteur. A continuación, ana-

1. Por profesionales de la prensa escrita debemos comprender a los periodistas, reporteros gráficos, dibujantes, fotógrafos, columnistas y, en general, a todos aquellos que aportan una obra integrada en una publicación periódica, como lo es un periódico o una revista. 
lizaremos en detalle el artículo 24, letra c) de la Ley 17.336, para lo cual se examinará su historia fidedigna. Como cierre, presentaremos una propuesta dogmática acerca de cuáles derechos de autor deben ser reconocidos a los profesionales de la prensa escrita, en lo que dice relación con las nuevas formas de aprovechamiento económico de una obra que no fue creada en un entorno digital, para lo cual ocuparemos material dogmático extraído del derecho comparado, especialmente ordenamientos como el italiano, que por su cercanía conceptual con nuestro sistema resulta de suyo útil.

\section{El estado de la cuestión en el derecho comparado}

Para examinar esta materia desde la perspectiva del derecho comparado, hemos escogido los sistemas jurídicos más representativos de las llamadas familias del derecho de autor, en los que, además, ha existido una alta litigiosidad sobre el asunto de este estudio. Por el lado del copyright, abordaremos la cuestión en el derecho estadounidense, el cual contiene importantes precedentes judiciales sobre la materia. ${ }^{2}$ Mientras que respecto del droit d'auteur, conoceremos la valiosa discusión generada en el entorno galo, la cual ha sido resuelta positivamente con reformas a sus cuerpos normativos, como el Código del Trabajo y el Código de Propiedad Intelectual, mediante la Ley 2009-669, de 12 de junio de 2009, que promueve la difusión y protección de la creación en internet, conocida como la «Ley Hadopi 1». Por último, cabe advertir

2. Para los efectos de este texto, por copyright nos referiremos a aquella conceptualización anglosajona del derecho de autor cuya raíz se encuentra en el Estatuto de la Reina Ana, de 1709, y que posteriormente es recogida por los demás países de la familia del Common Law. En términos generales se caracteriza por conceder una facultad a su titular para prevenir la copia de la obra protegida, de ahí que su foco se asienta en el objeto amparado y no en su creación. Esta orientación marcadamente económica influye que se considere como titulares originarios de los derechos de autor no solo a las personas naturales, sino también a las jurídicas. Del mismo modo, el reconocimiento de los derechos morales a los autores es sumamente restrictivo, y es posible tutelar por su intermedio objetos que no son propiamente creaciones autorales, como las grabaciones sonoras o la transmisión electrónica de imágenes o sonidos por medios inalámbricos. Por el contrario, droit d'auteur comprende el sistema jurídico latino del derecho de autor, cuya génesis está en las leyes francesas dictadas a partir de la revolución de 1789, y que fue adoptado por los países de la tradición del Civil Law, como Italia, España y los pertenecientes a Sudamérica. Este es un sistema esencialmente individualista en el que es relevante el acto de la creación, el cual es fruto solo del quehacer humano, de ahí que la obra concebida se encuentra estrechamente vinculada con la personalidad de su autor. Así, según este enfoque solo son amparables por el derecho de autor las obras creadas por las personas naturales que cumplan con el requisito de originalidad, por lo que todas las demás producciones vinculadas al quehacer literario, artístico o científico (por ejemplo, la fijación de sonidos o de imágenes y su posterior transmisión) que no hayan observado tales exigencias podrán ser protegidas, si el legislador lo estima, por medio de los llamados derechos conexos o vecinos. Asimismo, son notas destacadas de este sistema jurídico el reconocimiento amplio de los derechos morales a los autores, los cuales son considerados como exclusivos titulares originarios de sus obras, salvo que la ley contemple lo contrario. Sobre las diferencias entre el copyright y el droit d’auteur véase Stewart (1989: 6-10). 
que, a pesar de las diferencias dogmáticas entre los sistemas jurídicos mencionados, las soluciones a las que arriban sus tribunales de justicia son similares, lo que da cuenta de un interesante diálogo entre las tradiciones jurídicas.

\section{El estado de la cuestión en el derecho estadounidense}

Antes, nos parece necesario precisar dos consideraciones relativas a las disputas judiciales de los derechos de autor de los profesionales de la prensa escrita en el entorno digital en este ordenamiento. La primera es que la totalidad de las controversias jurídicas que se han generado son fruto de acciones presentadas por profesionales independientes ofreelance por usos no consentidos en el ámbito virtual. Esto se debe a que, tratándose de las creaciones de trabajadores dependientes dentro del ámbito de su trabajo, la Copyright Act de 1976 dispone que la titularidad originaria de dichas obras (work made for hire) recae en el empleador. En efecto, es considerado como el autor de las obras a menos que las partes, en un documento por escrito, hayan acordado la reserva de ciertos derechos a favor del trabajador. ${ }^{3} \mathrm{Al}$ tener el empleador la calidad de autor de esta obra por encargo, la ley no solo le atribuye los derechos para explotarla conforme a los métodos conocidos al tiempo de su creación, sino que además respecto de cualquier otra forma de aprovechamiento. Ello incluiría la reproducción y distribución digital de obras producidas inicialmente para un medio impreso (Nordemann, 2006: 613; Maseda Rodríguez, 2016: 53).

La segunda consideración se refiere a que estos profesionales independientes suelen estar vinculados con las empresas editoriales mediante simples contratos verbales, con lo cual no se encuentran sujetos al estatuto de las obras por encargo. Esto implica que sus creaciones son consideradas como aportes individuales que pasan a incorporarse a la obra colectiva de la cual forman parte (Merges, Lemley y Menell, 2010: 504). A modo de ejemplo, tendrían dicha condición los artículos escritos por los periodistas freelance que se incluyen en una edición de un periódico, pues según

3. Véase 17 US Code, párrafo 201, letra b. Como complemento, según 17 US Code, párrafo 101, las denominadas obras por encargo (work made for hire) comprenden dos supuestos: las obras preparadas por un trabajador en el ámbito de su empleo y las obras especialmente encomendadas como contribución a una obra colectiva, parte de una obra cinematográfica o de una obra audiovisual, traducción, complemento de otra obra, compilación, texto educativo, cuestionario, respuesta a cuestionario o atlas, en la medida en que exista un pacto expreso por escrito entre el empresario y el autor, en cuya virtud las partes le otorgan a tal creación el carácter de obra por encargo. De esta manera, si la obra encomendada no es ninguna de las mencionadas anteriormente o se carezca del acuerdo expreso indicando, entonces no estaremos frente a una work made for hire, por lo que se dispone que la titularidad originaria de la obra le pertenezca a su creador. En cuanto a los fundamentos económicos en que se asienta esta regla de asignación de derechos, por todos, véase Hardy (1988). Respecto a su génesis, véase Fisk (2003). Finalmente, un análisis de los casos judiciales más relevantes sobre esta doctrina puede verse en Gómez Abelleira (1999: 168-194). 
lo prescrito en la Copyright Act, en ausencia de un pacto expreso de transferencia de derechos por parte del autor, se presume que el titular de la obra colectiva sólo ha adquirido las facultades de reproducir y distribuir el aporte entregado como parte de la particular obra colectiva, o de una revisión de la misma, o una posterior obra colectiva de la misma serie (17 US Code, párrafo 201, letra c). Por consiguiente, el empresario no ostentaría ningún derecho sobre la contribución individual, cuyas facultades de explotación están reservadas para sus autores, y solo estaría autorizado para reproducir y distribuir dicho aporte en la medida en que se incluya en la obra colectiva que le pertenece (Jollymore, 1990: 22).

En este escenario, el aspecto debatido en cada una de las sentencias que estudiaremos se centra en determinar si la edición electrónica de una publicación impresa puede ser considerada como una revisión de la obra colectiva originalmente en papel. Por ende, si se estima que la publicación electrónica no es más que una revisión de la obra colectiva impresa, entonces el empresario puede llevar a cabo tal operación sin el consentimiento de sus autores. ${ }^{4}$ En caso contrario, si se juzga que estas compilaciones digitales no comparten la misma naturaleza que las obras en papel, necesariamente se deberá contar con el consentimiento de los profesionales de la prensa para llevar adelante esta nueva forma de explotación económica.

Para resolver esta interrogante, examinaremos en primer lugar el caso The New York Times Co. Inc. y otros con Tasini y otros, resuelto por la Corte Suprema en 2001, en el cual se pretendió fijar un criterio definitivo sobre este asunto. En segundo término, analizaremos los pronunciamientos judiciales posteriores emitidos por los tribunales inferiores, los cuales han entregado más luces acerca de esta materia.

\section{La sentencia de The New York Times con Tasini}

Este asunto fue iniciado por un grupo de seis periodistas independientes, los cuales demandaban la infracción a sus derechos de autor por parte de New York Times Company, Newsdays Inc y Time Inc. Así, sostenían que tal infracción tenía lugar debido a que las empresas periodísticas implicadas estaban autorizadas solo para publicar sus artículos en medios impresos, como The New York Times o Sports Ilustrated. Sin embargo, sin su consentimiento habían licenciado dichos textos a dos compañías de nueva tecnología.

4. Acerca del concepto de revisión, a fin de esclarecer su sentido, los autores destacan de manera reiterada que en la historia fidedigna de la Copyright Act quedó asentado que una compañía editorial puede reimprimir una contribución individual contenida en una edición anterior de una revista, para formar parte en una tirada posterior de la misma publicación. En cambio, el editor no estaría autorizado por este privilegio de revisión para alterar o modificar una contribución individual o incluirla en una nueva obra colectiva, como puede ser una revista distinta de aquella en que fue originalmente divulgada (Meitus, 2000: 758). 
Se alega que se habrían cometido dos infracciones. La primera tenía lugar al entregarse dichos textos a una sociedad (Nexis) que incorporó los mismos a una base de datos en línea de acceso restringido. La segunda se cometió al licenciar los artículos a una empresa (UMI), la cual produjo dos CD-ROM: uno, que contenía exclusivamente textos (NYTO), y el otro (GPO) que además reproducía imágenes. De esta forma, en el último CD-ROM los artículos se desplegaban en pantalla tal como se incluían en la edición impresa.

En primera instancia, el juez del Distrito Sur de Nueva York resolvió a favor de la posición de los editores. ${ }^{5}$ De acuerdo con el tribunal, los editores eran libres para reproducir y distribuir los artículos de los periodistas, ya que formaban parte de la revisión de una obra colectiva y no se estaba frente a una nueva creación. Sobre el punto en cuestión, el tribunal sostuvo que no existían diferencias sustantivas entre la edición impresa y la base de datos, debido a que esta última mantenía la misma selección, coordinación y arreglos de la obra original, debido a que en los resultados de búsqueda exhibía idénticos antecedentes de la edición impresa, como lo son el día y la página en que fue publicado antes el texto impreso. Finalmente, el juez argumentó que cuando la ley menciona que el titular de una obra colectiva (en este caso el editor) está facultado para hacer una revisión de la misma, no supone que dicha actividad se limite al medio o continente análogo (en este caso impreso), sino que pueden comprender también las ediciones en microfilm de publicaciones periódicas que son hace mucho tiempo conocidas.

Por su parte, el Tribunal de Apelación del Segundo Circuito revocó la decisión del juez inferior. A este respecto, determina que las bases de datos referidas no estaban incluidas dentro del concepto de mera revisión de una obra colectiva anterior. ${ }^{6} \mathrm{En}$ concepto de esta Corte de Apelación, las bases de datos eran similares a una nueva antología, en particular la confeccionada por Nexis, que comprendía millones de artículos recuperables tomados a su vez de miles de publicaciones. De ahí, se estimaba que se había perdido todo vínculo con las obras colectivas primogénitas, sobre las que tenían precisamente derecho las empresas editoras. A mayor abundamiento, el tribunal razonó que el ligamen con la edición impresa se abandonaba del todo, ya que en las bases de datos se presentaban los artículos desprovistos de los elementos anexos que caracterizan las publicaciones periódicas, como los titulares, anuncios publicitarios o fotografías.

Por último, la Corte Suprema, en una decisión dividida, mantuvo el dictamen del Tribunal de Apelación, deslizando en su voto de mayoría los siguientes aspectos para decidir la infracción a los derechos de autor de los periodistas:

5. Tasini con N.Y. Times Co., 972 F. Supp. 804 (SDNY 1997).

6. Tasini con New York Times Co., 206 F.3d 161 (2d. Cir. 1999). 
a) Las bases de datos implicadas no están amparadas por el derecho de revisión que goza el titular de una obra colectiva. El Tribunal Supremo, al examinar las bases de datos implicadas en el caso, determinó que estaban compuestas por un sistema de búsqueda que permitía acceder a cientos de artículos. El usuario podía desplegarlos en pantalla desvinculados de la edición impresa del periódico o revista, publicaciones que se caracterizan por disponer de elementos gráficos o de similar naturaleza alrededor de los textos. Por ello, para la Corte se estaba frente a una nueva antología o una publicación enteramente distinta a la obra colectiva inicial. De ahí que se requiera una autorización expresa por parte de los autores, unida a una nueva remuneración, dado que se trata de una explotación distinta de sus textos. ${ }^{7}$

Por su parte, en el disenso redactado por el juez Stevens se rechazó dicha argumentación, al sostener que un signo distintivo de la política de la Copyright Act es el principio de neutralidad de medios (principle of media neutrality). Según este principio, la conversión de la obra de un formato a otro no implica per se una infracción, como ocurre con la reimpresión de un texto a braille, a una lengua extranjera o a una microforma. Según este voto de minoría, la edición electrónica de las publicaciones en cuestión se identificaba correctamente con la fuente original de los textos, a través de elementos como su fecha o titular.

b) La analogía de las ediciones electrónicas a los microfilms es deficiente. Los editores, para apoyar su derecho de revisión a su obra colectiva, sostenían la existencia de una analogía entre las bases de datos y el microfilm. Para la mayoría de los miembros de la Corte Suprema tal criterio no era correcto, puesto que las reproducciones de un artículo impreso en una microficha, aunque apreciables con una lente, siempre aparecen en el contexto de una publicación periódica, y no de manera aislada como un reportaje separado. En cambio, en las bases de datos los artículos periodísticos se muestran desconectados de su contexto original, con lo cual no formarían por ello parte de una obra colectiva o de su revisión. En otras palabras, para la generalidad del Tribunal, la transferencia de un texto impreso a una base de datos no representa un mero cambio de formato.

Por ello, los autores de los artículos que inicialmente estaban incluidos en una obra colectiva tienen el derecho a obtener una nueva remuneración por una explotación que ahora tiene la naturaleza de individual en este nuevo medio tecnológico.

7. Acerca de este punto, en el voto de mayoría de esta decisión se esgrime que las bases de datos examinadas no son una mera revisión de las publicaciones impresas. Para obtener esta conclusión, en dicho voto se considera que el concepto de revisión denota la idea de una forma distinta de algo considerado por sus creadores o por otros como una misma obra. De ahí que, en este contexto, la totalidad de la base de datos no es reconocible como una nueva versión de la obra colectiva primitiva respecto de cada una de sus partes. Sobre lo dicho, véase New York Times Co. con Tasini, 533 U.S. 483, 500 (2001). 
c) Los potenciales efectos negativos económicos de una decisión favorable a los autores no deben restringir sus derechos. La mayoría de los ministros de la Corte Suprema se hacen cargo del argumento acerca de las devastadoras consecuencias económicas que sufrirían las editoriales si se acogiera las peticiones de los autores. Sobre esto, se resolvió que una especulación sobre potenciales daños no es un fundamento suficiente para restringir los derechos de los autores reconocidos por la Copyright Act. Se daba pie así a que las partes en el litigio iniciaran conversaciones para celebrar acuerdos que permitieran la reproducción electrónica de las obras protegidas, como sucede en otras jurisdicciones (particularmente el derecho francés). Con todo, en el voto de minoría, el ministro Stevens esgrimió que esta sentencia afectará el principal objetivo de la Copyright Act: promover una disponibilidad amplia de las creaciones de los campos de la literatura, música y demás artes al público.

Como cierre, resulta destacable mencionar ciertas opiniones de la doctrina con ocasión de los pronunciamientos emitidos en el caso New York Times con Tasini. La primera es que existía un particular interés en que la Corte Suprema estableciera un adecuado balance entre los derechos de los freelance sobre sus textos y el derecho de los editores para publicar sus obras colectivas en un entorno digital (Doscotch y McAuley, 2001: 231). En esta línea, se señalaba que una decisión favorable a los periodistas se podía estimar como un obstáculo para la diseminación de la información y la expansión comercial de la nueva economía (Segal Ayers, 2000: 55).

Esa inquietud de la dogmática resultó ser acertada, ya que la industria periodística, una vez notificada de la decisión de la Corte, eliminó de las bases de datos todos los textos de los autores que no habían cedido expresamente sus derechos, con el fin de evitar posteriores demandas. ${ }^{8}$ Luego, el balance que se pretendía que existiera entre las partes en conflicto todavía no se ha logrado, toda vez que los medios de prensa, por la enorme asimetría negociadora con los freelance, han impuesto como condición de todo encargo periodístico la transferencia previa por los autores de todos los derechos para explotar la obra, con el fin de permitir usos actuales como futuros (all-rights agreements). Bajo este esquema, los periodistas no recibirían una remuneración adicional por la utilización de sus obras en los medios digitales (O’Rourke, 2003: 605; Terry, 2004: 240).

Como consecuencia de este escenario de desprotección de los profesionales de la prensa, se ha postulado como solución que puedan negociar colectivamente sus derechos frente a los editores. Eso sí, para esto tendría que promulgarse una ley que exceptúe ese ámbito de la actividad económica de la legislación antimonopolio, la que prohíbe todo acuerdo entre competidores sobre precios u otras condiciones de comercialización. ${ }^{9}$

8. Véase Linda Greenhouse, «The Supreme Court: Copyrights; freelancers win in copyright case», The New York Times, 26 de junio de 2001, disponible en https://nyti.ms/2HgrOda.

9. En este sentido se ha presentado el proyecto de ley titulado The Freelance Writers and Artist Pro- 


\section{Los pronunciamientos judiciales posteriores a New York Times con Tasini}

Es necesario complementar el análisis de los derechos de autor de los profesionales de la prensa en el ámbito de los medios digitales con importantes decisiones judiciales posteriores al precedente examinado. En particular, resulta relevante analizar dos litigios iniciados por fotógrafos freelance en contra de la empresa editora de la revista National Geographic. Estos juicios se iniciaron debido a que dicha empresa comenzó en 1997 a comercializar un CD y un DVD que contenía una colección de los cien años de la mencionada publicación. Estas obras se titulaban The complete National Geographic.

En tales bases de datos se incluían diversas fotografías de estos profesionales que se contenían en las ediciones impresas de la revista. Sin embargo, para la comercialización de dicho soporte digital no se requirió la autorización de los fotógrafos, lo cual motivó la interposición de acciones judiciales por infracción de sus derechos de autor. Los demandantes sostenían que The complete National Geographic no era una simple réplica de las obras colectivas impresas, porque esta base de datos contenía otros elementos anexos, como secuencias gráficas o un buscador de imágenes. Por esto, se razonaba que se trataba de una creación distinta, destinada a un nuevo mercado, el cual era del todo diferente al de los medios impresos. De ahí que los autores alegaban que les correspondía una remuneración por la nueva explotación que se les daba a sus obras.

En contra, la empresa demandada indicaba que esta compilación digital de revistas no era más que una revisión de sus obras colectivas, por lo que no se requería una nueva autorización de los fotógrafos. La editora explicaba que The complete National Geographic no alteraba el formato original de la revista, toda vez que solo se escanearon sus páginas tal como aparecían en su versión digital. De esta forma, abarcaba textos, gráficos, anuncios publicitarios y créditos.

En el año 2005, el Tribunal de Apelación del Segundo Circuito se pronunció sobre esta controversia en el denominado caso Faulkner, y fijó un criterio favorable a las empresas editoras. ${ }^{10}$ Este tribunal efectuó la distinción entre las bases de datos de New York Times con Tasini con las comercializadas por National Geographic, las cuales sí debían ser consideradas una revisión de las revistas impresas. La Corte sostuvo que, respecto del primer caso, las empresas desmontaban por completo la edición impresa de sus publicaciones y creaban, por tanto, una nueva obra. Por el contrario, National Geographic realizaba en su CD-ROM una representación digital exacta a su versión original impresa. Por ende, se trataba de una revisión, cuya naturaleza no se alteraba

tection Act de 2002, tendiente a permitir la negociación colectiva de los derechos de los freelance. El contenido de dicho proyecto está disponible en http://bit.ly/2sEsUu2.

10. Faulker con Nat'l Geographic Enters, Inc., 409 F.3d 26 (2d. Cir. 2005). 
por la introducción de elementos informáticos menores, como lo eran las secuencias gráficas.

Con posterioridad, esta corriente judicial se confirmó por la sentencia dictada en el litigio Greenberg, de 2008. ${ }^{11}$ En esta decisión, dictada por el Tribunal de Apelación del Undécimo Circuito, se resolvió definitivamente que el CD The complete National Geographic era una revisión de las revistas impresas. Por tanto, no se infringían los derechos del demandante al incluir en esta base de datos sus fotografías. En sus razonamientos, la Corte manifestó que la obra utilizaba una idéntica selección, coordinación y orden que las revistas impresas subyacentes, lo que asimilaba esa base de datos al microfilm o microform.

Cabe añadir que un sector de la doctrina ha sido crítica sobre estos precedentes. Se sostiene así que el objetivo principal de la Copyright Act — promover incentivos a los autores para crear sus obras y difundirlas al público - se vería fuertemente afectado con una interpretación amplia del concepto de revisión. Se considera que los editores, al instaurar una nueva modalidad de explotación de sus obras colectivas, deberían retribuir a quienes hicieron posible que estos beneficios se produzcan (Ayer, 2009: 177). Asimismo, se añade que la interpretación de los Tribunales de Faulkner y Greenberg no es consistente con el precedente New York Times con Tasini, en particular cuando se argumenta que la demandada National Geographic estaba amparada por el principio de neutralidad de medios. Sobre ello, se piensa que dicho principio solo es aplicable cuando exista una traslación mecánica de una obra de un medio a otro. Pero esta operación no sucede si se transforma la naturaleza impresa de una revista a un formato digital para crear The complete National Geographic, pues esta última obra de carácter multimedia incorpora elementos relevantes, como animaciones o buscadores de imágenes, lo que implica una creación del todo diversa a la obra colectiva impresa (Dallal, 2007: 82-84).

Finalmente, a partir de este estado de la cuestión, cierta doctrina ha sostenido que es posible considerar que dentro del concepto de revisión de una obra colectiva se encasillarían las llamadas revistas digitales, en el caso de que sean una réplica exacta de la publicación impresa, las que pueden ser revisadas en línea o descargadas a un computador, para permitir al lector dar vuelta a las hojas virtualmente de manera semejante a la obra en papel (Koransky, 2009: 169). ${ }^{12}$

\footnotetext{
11. Greenberg con Nat'l Geographic Soc'y, 553 F. 3d 1244 (11th Cir. 20o8).

12. Para Lateef Mtima, las copias digitales ni siquiera deben ser consideradas revisiones, sino que deben ser clasificadas como versiones de archivo, como lo es el microfilm, puesto que no se ha alterado la obra original en ninguna forma substancial (Mtima, 2004: 422).
} 


\section{Recapitulación}

En el derecho estadounidense ha tenido lugar un intenso debate sobre los derechos de autor de los periodistas y fotógrafos freelance en relación con sus creaciones inicialmente incluidas en obras colectivas impresas, como periódicos o revistas, que luego pasan a ser explotadas como parte de una base de datos. De los precedentes judiciales revisados, es posible concluir que el editor tendría que contar con una autorización de los autores para explotar de forma digital las obras de los freelance. Ello en la medida que el medio electrónico utilizado por el empresario disponga de las creaciones (textos o fotografías) para su revisión por el usuario de una manera distinta de la presentada en la edición impresa (Gray, 2003: 650; Siprut, 2008: 529). Por el contrario, si la base de datos o plataforma electrónica no es más que una digitalización de la obra colectiva, y por ello las creaciones de los freelance son mostradas de manera idéntica que la publicación escrita, entonces el editor no deberá obtener el consentimiento de tales autores para dicha explotación, debido a que está amparado por el derecho de revisión, propio del titular de una obra colectiva. Finalmente, esta discusión no tiene lugar respecto de los profesionales de la prensa que tienen el carácter de trabajadores de la empresa editora, en atención a que por disposición legal la titularidad originaria de tales obras recaerá en la empleadora, a menos que en el contrato de trabajo se haya pactado lo contrario.

\section{El estado de la cuestión en el derecho francés}

La situación jurídica de los derechos de autor de los profesionales de la prensa, hasta antes de la llegada de los medios tecnológicos, era un asunto que interesaba esencialmente a la doctrina, pues no existían importantes disputas judiciales entre autores y editores (Deriux, 2010: 71). Sin embargo, este escenario se alteró diametralmente con la llegada de las nuevas tecnológicas en el ámbito de las publicaciones periódicas. De manera semejante a lo ocurrido en Estados Unidos, los profesionales de la prensa dieron inicio a una serie de acciones judiciales en contra de las empresas editoras, ya que estas empezaron a explotar las obras colectivas, como periódicos o revistas, a través de ediciones electrónicas en internet o mediante bases de datos, sin contar para ello con su consentimiento. Ahora bien, a diferencia del copyright estadounidense, en el derecho galo tales demandas fueron intentadas tanto por profesionales dependientes como freelance, en atención a que en dicho sistema jurídico el tratamiento a las obras creadas por los autores dependientes o por encargo es similar. $Y$ es que se dispone que las facultades patrimoniales sobre las creaciones recaen solo en la persona física creadora, lo que implica necesariamente que tenga que efectuar una 
cesión expresa de derechos para que un tercero disfrute de las mismas (Lucas, Lucas y Lucas-Schloetter, 2012: 173; Ahner y Touati, 2010: 82). ${ }^{13}$

Con todo, como consecuencia de esta creciente conflictividad, el legislador francés decidió regular esta materia mediante la Ley 2009-669, del 12 de junio de 2009. Como veremos, esta normativa se inclina hacia una postura más favorable para la industria de la prensa.

A continuación, analizaremos por separado la posición de los profesionales de la prensa en el ordenamiento francés con anterioridad a la reforma del año 2009, para luego dar un detalle del derecho vigente. Creemos que este estudio puede resultar ilustrativo para ensayar ciertas soluciones a esta cuestión en el derecho chileno.

\section{El estatuto de los profesionales de la prensa antes de la Ley 2009-669}

De acuerdo con la opinión común, tanto en virtud del texto de la Ley sobre Propiedad Literaria y Artística de 1957, como de las disposiciones del Código de Propiedad Intelectual pertinentes hasta 2009, los periodistas — tanto dependientes como independientes - como consecuencia del encargo realizado, transferían a los editores el derecho de reproducir solo sus textos correspondientes a la primera edición impresa del periódico o revista. Por tanto, cualquier otra reproducción, sea en un medio impreso diverso o en otro soporte, requería un consentimiento expreso de los autores (Varet, 2000: 364).

Bajo esa doctrina tuvo lugar el caso Plurimedia, en el cual por primera vez se discutió la explotación digital de textos originalmente impresos en el ámbito de internet. ${ }^{14}$ Este litigio se inició por una demanda presentada por el sindicato de periodistas de Francia y un grupo de periodistas dependientes, los cuales acusaban a la compañía Plurimedia de explotar sus textos en internet sin su autorización. La compañía se defendió alegando que dichos artículos le habían sido cedidos por el periódico Dernières Nouvelles d'Alsace, quien era el titular de los derechos de autor sobre la obra colectiva impresa donde figuraban los textos. El Tribunal ordenó una medida

13. Lo expresado se sostiene particularmente en el artículo L 111-1 del Código de Propiedad Intelectual, que establece que la existencia o la celebración de un contrato de trabajo o prestación de servicios no importa la derogación del disfrute de los derechos que la Ley concede al autor, como también en el artículo L 131-3, primer párrafo del mismo Código, que dispone que la transferencia de los derechos del autor está sujeta a la condición de que cada uno de los derechos transferidos sea objeto de una mención distinta en la escritura de transferencia y que el alcance de la explotación de los derechos cedidos esté delimitado en cuanto a su extensión, destino, ubicación y duración. En virtud de esta última norma citada, tanto para cierta doctrina como para la jurisprudencia reciente de la Corte de Casación, se debe negar toda validez a la cesión implícita de derechos del autor a favor de su empleador o comitente. Sobre esto último, véase Passa (1999: 36).

14. Union Syndicale des Journalistes Français CFDT et autres con Société Plurimedia, Tribunal Grande Instance de Strasburg, 3 de febrero de 1998. 
cautelar destinada a impedir la difusión en internet de las obras de los periodistas, pues consideraba que en los contratos colectivos suscritos por los trabajadores con el periódico en cuestión no se contemplaba la cesión de los derechos sobre las creaciones literarias en el campo digital, y que esto era una nueva forma de comunicación al público que requería un consentimiento expreso. ${ }^{15}$

Con posterioridad, los tribunales superiores fueron perfilando esta línea jurisprudencial con mayor profundidad. Un primer paso se encuentra en la sentencia dictada por la Corte de Apelación de Lyon, en el asunto Le Progrès, de 1999. ${ }^{16}$ Lo relevante de este litigio es que la editora, frente a una demanda de periodistas por el uso de sus obras en internet, presentó dos defensas, estas son, que disponía de la facultad de explotar digitalmente los textos de los periodistas por formar parte de una obra colectiva, y además que tal derecho de utilización se presumía por la relación laboral que unía a las partes involucradas. El primer argumento expuesto por la editora fue desestimado por la Corte, a cuyo entender sus derechos alcanzaban solo a la obra colectiva y no los aportes individuales de los autores, de modo que ellos conservaban sus facultades de explotación sobre sus textos, con la reserva de no competir con la publicación periódica, circunstancia fáctica que solo tiene lugar al momento de la primera impresión. ${ }^{17}$ En cuanto a la segunda defensa, tampoco fue acogida. A este respecto, el Tribunal de Apelación estimó, por un lado, que la existencia de un contrato de trabajo no implicaba la derogación de los derechos concedidos al autor por la ley especial y, por el otro, que la normativa laboral en específico disponía que toda publicación de un trabajo literario o artístico en otro periódico, ya sea de propiedad del empleador o de un tercero, requerirá un convenio que fije las condiciones económicas a favor del periodista profesional por esta nueva explotación. ${ }^{18}$

15. Se tuvo particularmente en vista para resolver la controversia el artículo L 131-6 del Código de Propiedad Intelectual, que dispone que toda cláusula de cesión de derechos para explotar una obra en una forma no previsible al tiempo de la celebración del contrato debe ser explícita y se debe estipular la participación correlativa en los beneficios que tal explotación conlleva a favor del autor, norma jurídica que la demandada no observó en este caso.

16. Sté. Groupe Progrès con Syndicat National des Jornalistes et autres, Corte de Apelaciones de Lyon, 9 de diciembre de 1999.

17. El Tribunal en este punto se apoyó en el artículo L 121-8, párrafo segundo, del Código de Propiedad Intelectual, que señala que respecto de las obras publicadas en periódicos o publicaciones, su autor mantiene sus derechos, a menos de pacto expreso, para reproducirlas o explotarlas de cualquier manera, bajo la condición de que dicha reproducción o explotación no implique una competencia con el periódico o publicación involucrada.

18. Las normas que se tuvieron en vista por el Tribunal para resolver esta causa fueron el artículo L 1111 del Código de Propiedad Intelectual y el artículo 761-9 del Código del Trabajo. Esta última disposición prescribe que la reproducción de un artículo o trabajo literario de un periodista profesional en más de un periódico o publicación periódica, distinta a la suya, supondrá un convenio escrito que regule esa nueva reproducción. 
El siguiente paso en esta evolución jurisprudencial es la sentencia dictada por la Corte de Apelaciones de París en el litigio Le Figaro, de 2000. ${ }^{19}$ Lo novedoso de esta controversia es que la demandada, propietaria del periódico Le Figaro, alegó como defensa la neutralidad de medios entre la edición impresa y la versión telemática de dicha publicación, ya que ambas compartían la misma naturaleza de obra colectiva, de la cual era titular. El Tribunal rechazó esta argumentación, pues en su opinión la publicación en internet no es idéntica a la impresa, debido a que solo contiene los aportes singulares de los autores, con exclusión de elementos fotográficos o figurativos. Por tal motivo, la concibe como una explotación individual — solo de los textos- y no del periódico en su integridad.

La ulterior fase es la sentencia pronunciada por la Corte de Casación en la causa Rillon, de $2001 .^{20}$ Este litigio se inició por una demanda presentada por un fotógrafo dependiente en contra de su exempleador Capital Media, en la cual reclamaba que el último había utilizado sus fotografías más de una vez sin contar con su consentimiento. El demandante mencionaba que solo autorizó la publicación de sus fotografías en la edición impresa del periódico de su exempleador, pero no autorizó su inclusión en la versión de internet de dicha publicación. La Corte de Apelaciones de Versalles desestimó la acción legal esgrimiendo que solo se requiere una nueva autorización por el autor en la medida que se utilicen sus obras en una publicación distinta de aquella en que fue originalmente divulgada, circunstancia que no tiene lugar respecto de las versiones digitales en internet. Ahora bien, la Corte de Casación invalidó la sentencia del tribunal inferior, pues en su consideración el trabajador cede por su contrato al empleador el derecho de reproducir su obra una sola vez. De esta suerte, se concluye que la publicación en otro medio, como es internet, requiere su autorización expresa.

Como cierre en esta evolución se debe mencionar la sentencia emitida por la Corte de Casación en el asunto Baudouin Eschapasse, de 2004. ${ }^{21}$ En este juicio un periodista dependiente reclamó a la empresa editora Sophia Publications la reproducción en el sitio web historia.fr de un conjunto de entrevistas de su autoría que ya habían sido publicadas en el medio impreso Historia.

La Corte acogió la demanda presentada desestimando cada una de las defensas esgrimidas por la editora. La primera de ellas se refería a que las entrevistas no eran obras protegibles, puesto que solo consistían en una trascripción de lo expuesto verbalmente por el entrevistado. Este criterio no fue admitido, toda vez que las entrevistas habían sido retranscritas para darles una forma literaria elaborada, por eso se

19. Sté. Gestion du Figaro con Syndicat National des Journalistes et autres, Corte de Apelaciones de París, 10 de mayo de 2000.

20. Jean Michel Rillon et autres con Sté. Capital Media, Corte de Casación de Francia, 12 de junio de 2001.

21. Société Sophia publicatons con Baudouin E., Corte de Casación de Francia, 30 de enero de 2004. 
trataban de creaciones amparables. La segunda defensa denegada aludía a la aplicación retroactiva de la Ley 2009-669 que, como veremos más adelante, dispone de un sistema favorable a las empresas editoras. En este punto, la Corte decidió que la nueva Ley que establece una presunción de cesión de los derechos de los periodistas en provecho del empleador no podía aplicarse a los contratos celebrados con anterioridad a su entrada en vigor. Por consiguiente, se colige que la empresa estaba impedida de reproducir estos artículos en nuevos soportes, como es internet, si no contaba con una cesión expresa del autor.

A modo de resumen, con anterioridad a la reforma legislativa de 2009, los profesionales de la prensa gozaban de una posición de preferencia frente a la industria editorial, puesto que en el caso de sus obras publicadas originalmente en medios impresos, la judicatura exigía la autorización ser utilizadas en plataformas digitales requería, lo cual conllevaba naturalmente el pago de una remuneración. Este panorama favorable a los autores se alterará drásticamente con la promulgación de la Ley 2009-669.

\section{El estatuto de los profesionales de la prensa a partir de la Ley 2009-669}

La Ley 2009-669 introduce un párrafo específico en el Código de Propiedad Intelectual titulado «Los derechos de explotación de las obras de los periodistas», que significa un verdadero cambio a los principios propios del droit dauteur en esta materia, pues acerca la legislación francesa al modelo de copyright (Deriux, 2010: 71). Recordemos que, conforme al marco normativo anterior, el profesional - tanto dependiente como freelance - mantenía sus derechos patrimoniales sobre sus creaciones, ya que solo se presumía una cesión de sus facultades tratándose de la primera edición escrita, por lo que cualquiera otra utilización requería su consentimiento (Lucas, Lucas y Lucas-Schloetter, 2012: 183). Por el contrario, la Ley de 2009 establece como regla general que, en virtud del contrato de trabajo o de prestación de servicios celebrado por un periodista profesional con una empresa periodística, se le ceden de manera exclusiva a esta última todos los derechos patrimoniales sobre las obras de dicho autor, sean o no publicadas, en la medida que se exploten conforme a las nuevas normas vigentes (artículo L 132-36 del Código de Propiedad Intelectual).

No es nuestro objetivo presentar una exposición detallada de este régimen cercano a la doctrina work made for hire. Sin embargo, daremos cuenta de las notas más relevantes relativas a la utilización de las creaciones en el ámbito de las nuevas tecnologías.

Un primer aspecto relevante es el extenso campo subjetivo de aplicación de las disposiciones recientes. La Ley 2009-699 determinó que quedan sometidos a esta transferencia automática de derechos los llamados periodistas profesionales, ya sean dependientes o freelance. Se asimilan así a dicha condición los colaboradores directos 
de redacción, los traductores, los redactores revisores, los corresponsales, los reporteros gráficos y los dibujantes (artículos L 7111-3, L 7111-4 y L 7111-5 del Código del Trabajo). ${ }^{22}$ En cuanto al beneficiario de la cesión de derechos, la Ley señala que será el denominado titular de la publicación (titre de presse), que comprende la organización del medio escrito a cuyo favor el periodista ha desarrollado su actividad. Ahora bien, en aquel supuesto que una sociedad controle diversas organizaciones titulares de publicaciones, tales entidades podrán celebrar convenios entre sí que les permitan difundir obras que le pertenecen a cualquier miembro del grupo. Eso sí, sujeto a la condición de que las publicaciones formen parte de una familia coherente de medios (famille cohérente de presse), listado que será determinado en el contrato que liga a cada una de estas editoras (artículos L 132-35 y L 132-39 del Código de Propiedad Intelectual, y el artículo L 7111-5-1 del Código del Trabajo). ${ }^{23}$

En cuanto a las contraprestaciones que reciben los periodistas profesionales por la utilización de las obras por el titular de la publicación, la Ley distingue los siguientes supuestos: i) respecto del uso de las creaciones en diferentes soportes por el titular de la publicación, el periodista solo tendrá como contrapartida su salario ordinario. Ahora bien, tal explotación deberá tener lugar en un período de tiempo fijado contractualmente, determinado en consideración a la periodicidad de la publicación y la naturaleza del contenido; ii) luego, toda utilización de la obra por el titular del medio con posterioridad al tiempo estipulado deberá ser remunerada, según se pacte individual o colectivamente; y iii) en relación con los usos no autorizados expresamente en la norma legal a favor del titular de la publicación, se indica que el autor tendrá derecho a una retribución adicional. Por último, cualquier transferencia de derechos para la explotación de las obras periodísticas a una persona distinta del titular de la publicación o de su familia coherente requerirá una autorización previa y expresa de su autor, la que podrá ser dada por un acuerdo particular o colectivo, sin perjuicio del ejercicio de sus derechos morales (artículos L 132-37, L 132-38, L 132-39 y L 132-40 del Código de Propiedad Intelectual, y artículo L 7113-3 del Código del Trabajo).

\section{Recapitulación}

Como hemos apreciado, el derecho de autor francés ha tenido una posición pendular respecto a la protección que se les concede a los profesionales de la prensa escrita. Es

22. Acerca de la cesión legal de los derechos de explotación tanto respecto de los periodistas que colaboran de manera permanente como ocasional con un medio de prensa, véase Léger (2011: 2.569).

23. La referencia a la «familia coherente de medios» tiene por propósito cautelar el derecho moral del periodista de divulgar sus textos en medios de comunicación que sean acordes con sus creencias personales, cuestión que fue objeto de discusión en el ámbito de las publicaciones electrónicas en la sentencia dictada por la Corte de Apelaciones de Bruselas en el caso Central Station con Association Générale des Journalistes Professionnels de Belgique, de 28 de octubre de 1997. 
así que hasta antes de la reforma legal de 2009, los editores solo disponían del derecho para publicar una vez las creaciones de los autores, de suerte que cualquier nuevo uso, en particular en el ámbito de las nuevas tecnologías, debía ser consentido y remunerado por los periodistas. Tal escenario normativo se modificó sustancialmente por la Ley 2009-669, puesto que en virtud del contrato que suscriba el dependiente o el freelance con la empresa periodística, se le transfieren a esta última de forma exclusiva los derechos de explotación sobre las obras producidas por dichos profesionales. Dentro de estos derechos se incluye expresamente la facultad que dispone el titular de la publicación o sus entidades relacionadas para publicar tales creaciones en internet, por lo que esa explotación no genera una remuneración adicional.

\section{El estado de la cuestión en el derecho chileno}

Consideraciones generales sobre los profesionales de la prensa escrita y las publicaciones periódicas en la Ley 17.336

El estatuto de los profesionales de la prensa escrita se contempla en el artículo 24, letra c) de la Ley 17.336, el que se aplica a los autores que presten sus servicios, como trabajadores dependientes o autónomos, en empresas periodísticas titulares de diarios, revistas y otras publicaciones periódicas. Sin perjuicio que esta disposición será objeto de un análisis detallado con posterioridad, estimamos pertinente dar a conocer ciertos alcances generales sobre la misma, en particular respecto a qué sujetos le resultan obligatorias sus disposiciones, lo cual nos permitirá establecer un primer marco de referencia conceptual sobre la cuestión objeto de este estudio.

En este sentido, la norma regula la relación —-referida a los derechos de autor-de dos sujetos perfectamente delimitados: por una parte, la empresa periodística que es editora de diarios, revistas y otras publicaciones periódicas y, por la otra, los autores que prestan sus servicios a favor de ella, ya sea como dependientes o independientes.

La empresa periodística se puede definir como aquel establecimiento industrial que edita de manera permanente y regular un diario o revista. ${ }^{24}$ Por su parte, en cuanto a los sujetos que prestan sus servicios a las empresas periodísticas, la norma en examen no determina con precisión a quiénes comprende. Su numeral 1 ocupa la expresión neutra «autores», por lo que puede abrirse la discusión acerca de si abarca solo a los periodistas o si sus efectos alcanzan a los llamados «colaboradores» de la prensa.

A nuestro parecer, el campo de aplicación de esta disposición es extenso, toda vez que según su tenor incluye un amplio elenco de creaciones confeccionadas por di-

24. Las notas del concepto de empresa periodística se extraen del artículo 73, inciso 2 del Decreto Ley 767 de 1925. 
chos agentes, como «artículos, dibujos, fotografías y demás producciones aportadas». En consecuencia, en atención al catálogo de obras mencionadas, ya sean literarias o gráficas, es posible deducir que quedan sometidos a este estatuto los llamados «profesionales» de la prensa escrita, con lo cual esta categoría cubriría a los periodistas, fotógrafos, dibujantes, traductores, revisores y editores.

Ahora bien, una de las cuestiones claves sobre el vínculo de estos dos sujetos consiste en determinar si las obras mencionadas en el encabezado del artículo 24 letra c) de la Ley, a saber, diarios, revistas y otras publicaciones periódicas, se reducen en exclusiva a los medios impresos, o bien, si es posible incluir dentro de ese género las denominadas publicaciones electrónicas.

En este punto, puesto que a la fecha de la publicación de la Ley 17.336 no estábamos frente al entorno digital, es incuestionable que la referencia normativa a los diarios o revistas es solo a los soportes impresos. Sin perjuicio de ello, surge la duda si un concepto más amplio como "publicación periódica» pueda ser interpretado en términos más generales para incluir dentro del mismo las nuevas formas de comunicación social.

Acerca de esto, estimamos que existirían importantes argumentos normativos para considerar que la expresión «publicación periódica» en nuestro ámbito legal se circunscribe a aquellas obras que cuentan con un soporte material, de modo que quedarían excluidas las llamadas publicaciones electrónicas o en línea. ${ }^{25}$

Para sostener esta posición, en primer término, se debe tener en cuenta tanto la definición de "publicación» vigente a la fecha de promulgación de la Ley 17.336 - texto que se tuvo a la vista al momento de redactar el artículo 24 letra c) -, como el concepto de «publicación» agregado por la Ley 19.914, de 2003, que es el vigente. En este sentido, en el original artículo 5 letra o) de la Ley 17.336, se indicaba que por «publicación» se debía entender «la reproducción de la obra en forma tangible y su puesta a disposición del público mediante ejemplares que permitan leerla o conocerla visual o auditivamente». ${ }^{26}$ Luego, en el actual artículo 5 letra o) de la Ley 17.336 se dispone que:

25. En contra, en el ámbito del derecho español, Jiménez Martínez (2005: 49-50). Esta autora reconoce que el concepto legal de publicación periódica exige la edición de ejemplares, los que deben constar en un soporte material. No obstante, esgrime que se debería incluir dentro de esta categoría las publicaciones electrónicas - sin la existencia de ejemplares-, puesto que de lo contrario se le privaría a los autores de tales obras de los beneficios que la normativa del derecho de autor le concede a los demás creadores de las obras impresas.

26. Dicha norma, inspirada evidentemente en el artículo 6 de la Convención Universal sobre los Derechos de Autor resultaba en extremo restringida, ya que incluso no consideraba dentro del concepto de publicación aquella que tiene lugar mediante la reproducción de una obra por medio de fonogramas (Evangelio Llorca, 2013: 369-370). 
publicación de una obra, interpretación o ejecución fijada o de un fonograma significa la oferta al público de la obra, interpretación o ejecución fijada o del fonograma, con el consentimiento del titular del derecho, siempre que los ejemplares tangibles se ofrezcan al público en cantidad suficiente. ${ }^{27}$

Esta definición, al requerir el ofrecimiento de ejemplares al público, da cuenta de la necesidad de poner en circulación copias tangibles de la obra, lo que por tanto relega de la noción normativa de «publicación» la mera disposición electrónica o digital de una obra. ${ }^{28}$

Un segundo elemento de apoyo a nuestra posición se encuentra en el artículo 24, letra c), numeral 2 de la Ley. Esta norma, al tratar la situación jurídica del periodista independiente, indica que por el encargo de la obra se le otorga a la empresa periodística el derecho para publicar su creación respecto de la primera edición después de haber efectuado su entrega, luego de lo cual el autor puede disponer libremente de ella. A partir de esto, pensamos que esta regla no resultaría aplicable al entorno digital, en atención a que la puesta en línea de un texto o fotografía, por su permanencia indefinida en el tiempo, no se encasilla enteramente en la noción de primera edición, propia de los medios de prensa escrita. ${ }^{29}$ En este sentido, la norma examinada se construye bajo el supuesto de que el autor independiente podría aprovechar en el futuro su obra, una vez efectuada la primera edición de la publicación por la empresa comitente, circunstancia fáctica que no se presentaría en la edición digital, la que se mantiene accesible de manera ilimitada en el tiempo.

27. Esta disposición, que se aprecia de alcances más amplios que la revisada previamente al incorporar la fijación sonora, tiene su fuente directa en el artículo 17.6, numeral 8, letra e) del capítulo 17 del Tratado de Libre Comercio celebrado entre Estados Unidos y Chile.

28. En el ámbito del derecho español, Garrote llega a una similar conclusión, puesto que sostiene que al poner una obra en un sitio web no significa la publicación de la misma, puesto que no se verifica el requisito de que haya un número de ejemplares suficientes para satisfacer razonablemente las necesidades del público, por lo tanto se podrá entender que hay divulgación, pero no publicación (Garrote Fernández-Díez, 2003: 161). En esta misma línea, según Carbajo, para admitir dentro del concepto de publicación la explotación en línea se requiere una reforma legislativa, ya que tal idea hasta ahora solo contempla la entrega de ejemplares distribuidos masivamente en el público (Carbajo Cascón, 2002: 51). Comparten ese juicio para el derecho de autor estadounidense Schechter y Thomas (2003: 81). Sin perjuicio de lo dicho, para otros la exigencia de «ejemplares tangibles» se cumpliría con la puesta a disposición de la obra a través de un sitio de internet, ya que con ello se podría acceder por muchas personas a tal ejemplar, leerlo o escucharlo, e inclusive copiarlo (Schuster Vergara, 1997: 246).

29. Una de las acepciones de la palabra «edición» contenida en el Diccionario de la Lengua Española confirma que el concepto de primera edición se refiere a una tirada específica de ejemplares, lo cual se distancia de la puesta en línea. Así, se indica por edición: «2. f. Conjunto de ejemplares de una obra impresos de una sola vez, y, por ext., la reimpresión de un mismo texto. Edición del año 1732. Primera, segunda edición». 
Por los motivos antes esgrimidos es que consideramos que el concepto de publicación en este ámbito se circunscribe solo a las publicaciones periódicas impresas.

Finalmente, como una última observación preliminar, se debe apuntar que los periódicos, revistas y publicaciones análogas, con independencia de su soporte impreso o digital, son consideradas por la doctrina como obras colectivas..$^{30}$ Así las cosas, lo característico de las obras colectivas es que son creadas a partir de la iniciativa de una persona - en nuestro caso, una empresa periodística - que coordina todos los aportes individuales concebidos con la finalidad de formar un todo, contribuciones efectuadas por los autores bajo la subordinación de quien los dirige..$^{31}$

La consecuencia de la particular génesis de este tipo de obra es que la titularidad de los derechos sobre la misma recae en el organizador o coordinador. Esto con exclusión de los autores de los aportes singulares, los cuales de todas formas podrán separadamente explotar sus contribuciones, en la medida que cumplan con el requisito de originalidad (Berdaguer Mosca, 2010: 253-255). Adicionalmente, la doctrina destaca que las obras colectivas, al alterar el principio de autoría - pues se atribuye la titularidad de las mismas a quien no es creador-, son solo una ficción legal tendiente a facilitar la explotación de este tipo de producciones, de forma que su carácter excepcional impone que sea aplicada en términos restrictivos (Saiz García, 2000: 266). ${ }^{32}$

A partir de lo dicho, respecto de los profesionales de la prensa - ya sea trabajadores o independientes- que aportan a un medio de comunicación exclusivamente digital, al no ser aplicable el artículo 24 letra c) de la Ley, entendemos que la asignación de los derechos de explotación a la empresa titular de dicha publicación se podría regular conforme al estatuto de las obras colectivas. Esta última cuestión esbozada, a pesar de su relevante interés, no será objeto de un tratamiento separado en las siguientes líneas, puesto que el asunto central de este estudio es determinar de qué derechos de autor gozan los profesionales de la prensa escrita respecto de sus obras

30. La mayoría de la doctrina comparada le otorga la calidad de obra colectiva a los periódicos, revistas y publicaciones periódicas. A favor véase Navas Navarro (2015: 388-391); en contra, Rogel Vide (2013: 18-21).

31. Sobre las notas elementales de las obras colectivas aplicadas a las publicaciones periódicas, véase Jiménez Martínez (2005: 55-60). En cuanto al origen de la noción de obra colectiva, Rodríguez Tapia (1997a: 45) señala que tiene su fuente en Francia, y surge de la necesidad de calificar al Diccionario de la Real Academia de la Lengua, creado a instancia de dicha institución, cuyos aportes individuales se funden en un todo común resultante, por lo que no pueden atribuirse derechos separados a cada uno de los intervinientes.

32. En el caso de nuestro derecho, es evidente que esta ficción legal obedece al interés de proteger la inversión efectuada por el organizador para confeccionar la obra colectiva, puesto que para la asignación originaria de derechos sobre la misma no se requiere que realice actividad creativa alguna. Sobre esta misma orientación en el derecho italiano y francés, véase Navas Navarro (2015: 288-389). 
creadas inicialmente para un medio impreso, las cuales posteriormente son explotadas a través de los nuevos formatos digitales.

En síntesis, podemos sostener que el artículo 24 letra c) de la Ley solo será aplicable respecto de aquellas obras confeccionadas por profesionales de la prensa que se incorporen en diarios, revistas y publicaciones periódicas exteriorizadas en soportes materiales o tangibles. Acerca de lo dicho, se debe poner en relieve que tales ejemplares no se limitan solo a las ediciones impresas, sino que es posible incluir otros continentes físicos, como el CD-ROM. ${ }^{33}$ Por último, respecto de los profesionales de la prensa que aportan a un medio exclusivamente digital, al no ser aplicable el artículo 24 letra c) de la Ley, la asignación de derechos patrimoniales a favor de la empresa periodística se reglamentará conforme a la normativa de las obras colectivas. ${ }^{34}$

Los derechos que se le conceden a los profesionales de la prensa por el artículo 24 letra c) de la Ley 17.336, y su posible adaptación al entorno digital

Como hemos adelantado, el artículo 24 letra c) de la Ley 17.336 resulta, por su antigüedad, a todas luces insuficiente para reglamentar las nuevas formas de explotación digital, lo que conlleva a problemáticas dogmáticas muy similares a las revisadas en otros sistemas jurídicos. En este orden, para acercarnos a responder la interrogante planteada creemos necesario examinar de manera previa la historia fidedigna del artículo 24 letra c) de la Ley, para luego revisar sus alcances normativos y, por último, dar cuenta de su aplicación en el ámbito digital.

\section{La historia fidedigna del artículo 24 letra c) de la Ley 17.336}

El vigente artículo 24 letra c) fue una de las disposiciones que experimentó una mayor discusión durante la génesis de la Ley 17.336 en el Congreso Nacional. Es así que en la iniciativa presidencial esta materia se encontraba regulada de manera dispositiva, y por ello menos favorable a los periodistas, circunstancia que varió notoriamente en la tramitación parlamentaria, en atención a la influencia que en ella tuvo el gremio de estos profesionales.

En este contexto, el mensaje presidencial proponía un estatuto diferenciado para periodistas dependientes e independientes. Acerca de los primeros, se consignaba que respecto de las creaciones no suscritas por sus autores se consideraban transferidos todos los derechos a favor de la empresa periodística, mientras que las obras firmadas por sus autores solo se estimaba transferido el derecho de publicación por cinco años, salvo pacto en contrario. Ahora bien, no se contemplaba el derecho de remuneración adicional al dependiente por obras en otras publicaciones.

33. Similar opinión en el derecho español tiene Jiménez Martínez (2005: 48).

34. Sigue esta opinión para el derecho español, con las debidas matizaciones, Berdaguer Mosca (2010: 289). 
En cuanto a los independientes, se establecía que solo se transfería el derecho para publicar la producción. Este derecho debía ser ejercido por la empresa en el plazo de 90 días contados desde la entrega por el autor, luego del cual este último podía disponer libremente de ella, a menos que se pactara lo contrario. ${ }^{35}$

A su vez, es necesario subrayar que esta reglamentación no tenía el carácter de imperativa por dos motivos. Primero, en su encabezado se señalaba que las normas legales sobre obras colectivas eran aplicables a falta de convenio con los autores, $\mathrm{y}$ segundo, debido a que el proyecto de ley establecía como regla general que toda la normativa sobre derechos patrimoniales regía solo en defecto de estipulación de las partes. ${ }^{36}$

Esta propuesta presidencial recibió críticas negativas en el Congreso Nacional, las que alteraron de forma significativa su enfoque inicial. En primer término, se estableció la imperatividad del artículo 24 letra c) de la Ley, con lo que tuvo la calidad de derecho necesario para las partes..$^{37}$ En segundo lugar, se consagró el derecho a remuneración adicional a favor de los autores por publicaciones en distintos periódicos sin necesidad de contar con su autorización previa, ya sea que pertenezcan o no a su empleador. ${ }^{38}$ En tercer término, respecto de los autores dependientes se contempló que no debía limitarse temporalmente el derecho de publicación de la obra por su empleadora, de ahí que se indicó que está facultad sería indefinida en el tiempo y se podría ejercer cuantas veces se crea necesario por la empresa periodística. ${ }^{39}$ Finalmente, sobre los autores independientes, se alteró la regla respecto a la temporalidad para el ejercicio del derecho de publicación por el medio, indicándose que tal potestad exclusiva se mantenía por una sola vez hasta la primera edición. ${ }^{40}$

En síntesis, de la historia fidedigna de la norma en examen se puede deducir que el legislador ha pretendido satisfacer adecuadamente los intereses de las partes involucradas. En este sentido, a fin de que la empresa periodística pueda explotar las obras

35. Esta normativa se encontraba reglamentada en el artículo 26, letra c), numeral 1 del Mensaje Presidencial del 30 de diciembre de 1968, el cual puede ser revisado en «Historia de la Ley 17.336», Biblioteca del Congreso Nacional, folio 13, disponible en http://bit.ly/2HiOzNG.

36. El artículo 100 del mensaje presidencial decía: «Las normas de la presentes ley que regulan los derechos patrimoniales de los titulares de los derechos de autor y conexos son supletorias de la voluntad de las partes». La disposición propuesta fue duramente criticada en la Comisión de Constitución de la Cámara de Diputados, al indicarse que la regla de supletoriedad equivalía a convertir en letra muerta las normas tutelares de la Ley, ya que los autores podrían renunciar a las mismas por imposición de la voluntad de su contraparte. De este modo, se modificó su tenor drásticamente, al indicarse que los derechos patrimoniales tendrían la calidad de irrenunciables, conforme dice el artículo 86 vigente de la Ley 17.336 («Historia de la Ley 17.336», 131-132).

37. «Historia de la Ley 17.336», folio 159 .

38. «Historia de la Ley 17.336», folio 188.

39. «Historia de la Ley 17.336», folio 210.

40. «Historia de la Ley 17.336», folio 210. 
de los profesionales de la prensa - en especial de sus empleados- se le concede un derecho de publicación sobre las mismas. Desde una perspectiva inversa, a dichos autores que tengan el carácter de trabajadores se les otorga un derecho de remuneración adicional por el uso de sus obras en publicaciones distintas a las que prestan sus servicios. Adicionalmente, se debe mencionar que este tratamiento tuitivo a favor de los profesionales de la prensa tiene un diferente enfoque si se está en presencia de empleados o independientes. Como cierre, se debe agregar que las prescripciones del artículo 24 letra c) tienen el carácter de derecho necesario.

\section{Examen exegético del artículo 24 letra c) de la Ley 17.336}

El artículo 24 letra c) de la Ley contiene dos tipos de regulación para profesionales de la prensa, que dependen de su calidad de trabajador dependiente o independiente. En el primero de sus numerales se reglamenta el estatuto de los periodistas y colaboradores de prensa dependiente, mientras que en el segundo se detalla la situación jurídica de los independientes. A continuación, examinaremos ambos por separado.

a) El profesional de la prensa dependiente. El artículo 24 letra c), numeral 1, inciso 1 de la Ley establece la primera regla del régimen jurídico aplicable a los dependientes. Así, dispone que:

La empresa periodística adquiere el derecho de publicar en el diario, revista o periódico en que el o los autores presten sus servicios, los artículos, dibujos, fotografías y demás producciones aportadas por el personal sujeto a contrato de trabajo, reteniendo sus autores los demás derechos que esta ley ampara.

Como se advierte, la empresa periodística adquiere por el solo ministerio de la Ley el derecho para publicar las obras que sean desarrolladas por sus trabajadores (Uribe Corzo, 2007: 54). Por ello no se requiere que el trabajador transfiera el derecho de publicación a favor de su empleador, debido a que tal efecto es una consecuencia de la existencia de un contrato de trabajo (Walker Echenique, 2014: 11). Este último instrumento a su vez determina las obras específicas que serán atribuidas al empleador, ya que serán las que dicen relación con la función específica que el autor dependiente desarrolla en la empresa. De esta manera, se excluyen de este régimen las creaciones alejadas del desempeño de su cargo. ${ }^{41}$

Una segunda observación acerca de esta norma dice relación con precisar qué se debe comprender por derecho de publicación, el cual se le concede a la empresa periodística. Acerca de ello, como se examinó previamente, el concepto normativo de publicación supone dos actividades: la reproducción de la obra en un medio tan-

41. Para la doctrina española lo dicho es consecuencia del principio de ajenidad en los frutos, que es propio del contrato de trabajo (Soler Masota y Luque Parra, 1999: 608-609; Walker Echenique, 2014: 111). 
gible y la posterior distribución de los ejemplares donde consta la misma, que según el texto de la Ley, pueden revestir la forma de diarios, revistas u otras publicaciones periódicas.

Este derecho es de carácter indefinido, puesto que no está afecto a un límite temporal, ni tampoco se agota por el número de veces que es ejercido en el tiempo, por lo cual el empresario puede publicar las creaciones de sus trabajadores tantas veces como estime pertinente, sin estar constreñido a la llamada «primera edición». ${ }^{2}$

Asimismo, se debe apuntar que este derecho de publicación de la empresa periodística respecto de las obras creadas por sus dependientes no tiene como contrapartida una carga de explotar la misma. En otras palabras, la empleadora está investida de la facultad de decidir si inserta o no el aporte del autor dependiente en su publicación (Walker Echenique, 2014: 129).

El último alcance que debe hacerse a esta primera regla es que la asignación del derecho de publicación en favor de la empleadora no implica el pago de una retribución adicional para el autor, sino que basta para justificar tal concesión la remuneración pactada en el contrato de trabajo, lo que no es más que una manifestación del objeto y fin perseguido por las partes en la relación laboral. ${ }^{43}$

A continuación, pasaremos a revisar la segunda regla del régimen jurídico aplicable a los trabajadores, que se dispone en el artículo 24 letra c), numeral 1, inciso 2, primera parte, de la Ley 17.336, que dice:

La publicación de esas producciones en otros diarios, revistas o periódicos de la misma empresa, distintos de aquel o aquellos en que se presten los servicios, dará derecho a sus autores al pago adicional del honorario que señale el arancel del Colegio de Periodistas de Chile.

Este inciso se encuentra directamente relacionado con el anterior, de modo que tienen que ser interpretados en forma conjunta para que sean comprendidos de manera correcta. Como veíamos, el primero se refiere al supuesto en que la empresa periodística «adquiere el derecho de publicar» la obra del trabajador. Luego, este segundo dice relación con un derecho a un pago adicional de un honorario que se le otorga al trabajador según disponga el arancel del Colegio de Periodistas de Chile. ${ }^{44}$ La condición habilitante para recibir ese pago consiste en que la empresa periodística (empleador) publique una obra de algunos de sus trabajadores en un medio de co-

42. «Historia de la Ley 17.336», folio 210.

43. Para una similar opinión para el derecho español, véase Yagüe Blanco (2017: 32).

44. El arancel de referencia del Colegio de Periodistas se encuentra en su sitio web, disponible en http://bit.ly/2 $\mathrm{Hl}_{3} \mathrm{UNs}$. En contra, Schuster Vergara (2009: 377) sostiene que el arancel establecido en la norma no existe, luego de la derogación en 1976 de la facultad que poseían los colegios profesionales de fijar honorarios, de ahí que esta norma no sea aplicable en la actualidad. 
municación del cual sea titular (diario, revista o periódico) distinto de aquel en que preste su trabajo contratado.

El sentido de la norma se puede ilustrar con el siguiente ejemplo. Se trataría de una empresa periodística que es titular de distintos medios de difusión y que contrata un periodista para realizar su trabajo en tres de ellos. De esta situación sería posible deducir en términos generales dos hipótesis.

La primera hipótesis consiste en que la empresa publique las producciones de este trabajador precisamente en esos tres medios para los que ha sido contratado. En este caso, no se generaría la remuneración adicional a la que se refiere la norma indicada, porque esta disposición contempla la posibilidad de cumplir las labores estipuladas en más de un medio de difusión (perteneciente a la misma empresa periodística), cuando habla de «aquel o aquellos» diarios, revistas o periódicos pertenecientes al empleador. Aquí resulta esencial la utilización del pronombre plural «aquellos», que pone de manifiesto que los medios de difusión que pertenecen a la empresa periodística, donde es posible prestar servicios, pueden ser más de uno. De modo que si las producciones se difunden en exclusiva en ellos, nos encontramos dentro del marco del contrato, y no se debería dar lugar, por ende, al pago adicional señalado. ${ }^{45}$ Vemos

45. Estimamos que esta interpretación se encuentra acorde con el tenor literal de la letra c), número 1, del artículo 24 de la Ley 17.336 (véase el inciso 1 del artículo 19 del Código Civil). Pero también con su intención o espíritu, que pensamos pretende que se devengue el honorario adicional en los supuestos de publicaciones que se encuentren fuera de las funciones descritas en el contrato de trabajo (véase el inciso 2 del artículo 19 del Código Civil). Sin embargo, a simple vista de la historia fidedigna de este precepto parecería no coincidir con nuestra posición, debido a que algunos parlamentarios, como el senador Fuentealba, entendían que al periodista contratado para prestar sus servicios en distintas publicaciones de una misma empresa - lo cual se puede hacer - se le debía pagar en todo evento una remuneración de acuerdo con el arancel del Colegio de Periodistas. Pareciera entonces que se buscaba siempre el pago del honorario adicional cuando el trabajador fuera contratado para prestar labores en distintos medios de difusión del mismo empleador («Historia de la Ley 17.336», folio 266). Por nuestra parte, consideramos que la discusión que se generó en torno a este punto entre los senadores no fue del todo clara. Más bien, se advierte una confusión entre los senadores sobre el aspecto que realmente se estaba debatiendo. Por un lado, la factibilidad de que un profesional de la prensa pueda prestar sus servicios en distintos medios del mismo empleador y, por la otra, si en dicha hipótesis se cobra o no el pago del arancel en cuestión. Esto queda de manifiesto cuando el senador Sule desea que se vote en particular la expresión de la norma «o aquellos», a fin de zanjar los efectos de la propiedad intelectual que se pueden generar, en particular el pago del arancel, y el senador Luengo le responde que no, ya que «eso sería casi como impedir que una persona pudiera trabajar en varios diarios o para una empresa que tiene varios periódicos» («Historia de la Ley 17.336», folio 267). Por último, queremos advertir que no concordamos con aquella interpretación referida a que siempre se debería pagar el honorario adicional, en el caso de que un profesional es contratado por una empresa periodística para trabajar en varios de sus medios de difusión, y se publicarán sus obras en cualquiera de ellos, pues aquí, ¿cuál sería la razón de la remuneración ordinaria - por ejemplo, el sueldo- que percibe el trabajador como consecuencia de su contrato? En este tipo de casos, la contraprestación del trabajador que persigue la empresa periodística - que 
cómo el uso de ese pronombre se hace en contraposición a las publicaciones efectuadas en «otros diarios, revistas o periódicos» de la misma empresa, pero en los cuales el trabajador no ha sido contratado para desarrollar sus labores. Ciertamente, en esta hipótesis es donde se genera el derecho a recibir la remuneración adicional.

La segunda hipótesis es que el empleador publique algunas de esas producciones, en un medio del cual es titular, pero donde el trabajador no presta sus servicios. Según apuntábamos, en este caso sí se devengaría la retribución fijada en el arancel del Colegio de Periodistas de Chile. Cabe advertir que este derecho al honorario se distingue de aquellos derechos de explotación descritos en el artículo 18 de la Ley. Se aprecia entonces que no existe una titularidad absoluta de la obra, ya que el empleador puede publicar la misma aun cuando esta posibilidad no haya sido consentida por el profesional en el contrato de trabajo. Por consiguiente, no existe un señorío absoluto sobre la obra creada, sino solo se faculta al trabajador autor para exigir una prestación dineraria a su empleador que utiliza su creación. De esta suerte, este trabajador queda, más bien, asimilado a la figura de un acreedor. ${ }^{46}$

Del análisis de estas hipótesis, creemos que este precepto impone a la empresa periodística pactar con claridad la naturaleza de sus funciones y los medios de difusión en los que el trabajador desarrollará su labor, ya que ello incide en su posterior ejercicio del derecho contenido en la disposición en análisis. ${ }^{47}$ A nuestro entender, la importancia de determinar en qué consistirán los servicios y dónde se desarrollarán reside en la necesidad de un nexo causal entre la tarea debida y la obra que se deriva de esa labor, pues dicho nexo justifica que la empresa periodística adquiera «el derecho de publicar» las «producciones aportadas por el personal sujeto a contrato de trabajo» (inciso 1, numeral 1, letra c) artículo 24 de la Ley 17.336).

No obstante lo anterior, tal esquema puede perder su justificación si el contrato contempla un campo de actividad muy amplio, que a larga no guarde relación con los servicios que ejecuta el trabajador en realidad, pues esto significaría que la empresa periodística pueda ser titular de todas las creaciones que el trabajador desarrolle en

justifica para ella el pago de la remuneración y, por ende, la celebración del contrato de trabajo- se traduce normalmente en un resultado esperado, como puede ser un artículo periodístico o una fotografía. Si el resultado corriente de este trabajo no es cubierto por la remuneración del contrato, sino por una indicación especial contenida en la Ley, no se entiende su razón y, por consiguiente, de la necesidad del contrato de trabajo. De hecho, para la empresa le resultaría más conveniente contratar al trabajador solo en uno de sus medios, pues en ese caso, sin duda, no se devengaría el honorario mencionado.

46. Sobre las diferencias entre la remuneración derivada del ejercicio de los derechos exclusivos de explotación y el derecho de simple remuneración, en el entorno español, pero que resulta similar al nuestro en este punto, véase Cabedo Serna (2011: 160-164).

47. El carácter laboral de este derecho resulta evidente, puesto que conforme al artículo 24, letra c), numeral 1, inciso 3 de la Ley, la prescripción para su cobro se suspende a favor del autor mientras está vigente el contrato de trabajo. 
todos sus medios de difusión, aun cuando se trate de instancias en que no preste realmente sus servicios. Por consiguiente, las cláusulas que contengan áreas de actividad muy extensas pueden llegar a comportar que el derecho de los trabajadores a obtener el honorario adicional resulte inoperante.

Para examinar la eficacia de estas cláusulas en cuanto a su amplitud, creemos que un factor relevante consiste en determinar cuál es la función real que desempeña el trabajador en la empresa. Recuérdese la importancia que se otorga en nuestro ámbito laboral a la aplicación práctica que las partes efectúan del contrato a la hora de determinar el alcance de sus cláusulas (Gamonal Contreras, 2014: 178 y ss.).

Así las cosas, aquella cláusula que comprenda más labores, en distintos medios de difusión, que las acometidas efectivamente podría estimarse que afecta el devengamiento del honorario indicado $y$, de esa forma, ir en contra de un derecho que tiene el carácter de irrenunciable (artículo 86 de la Ley 17.336). Por tanto, esta eventual fórmula de asignación general de encargo laboral estaría privada de eficacia, puesto que significaría un detrimento para el trabajador, al cual se le impediría obtener el pago del honorario adicional..$^{48}$

Por último, examinaremos la tercera regla del régimen jurídico aplicable a los dependientes, que se dispone en el artículo 24 letra c), numeral 1, inciso 2, segunda parte, de la Ley 17.336, que dispone: «Si la publicación se hace por una empresa periodística distinta de la empleadora, aquella deberá pagar al autor o autores el honorario que establezca el mencionado arancel».

Acerca de esta norma, es necesario subrayar que consagra un derecho a un honorario en favor del autor que debe asumir un tercero ajeno a la relación laboral. Por este motivo, es posible incardinar este supuesto como un tipo de licencia legal, pues en virtud de ella se autoriza la utilización de una obra ajena, en determinadas condiciones, lo que implica como contrapartida el pago de una suma de dinero fijada de antemano por la norma. ${ }^{49}$ Se trata, por tanto, de una excepción a lo establecido en el artículo 19 de la Ley, y por ello no admite una interpretación extensiva. En cuanto al fundamento de la incorporación de esta regla, en la historia de la Ley se mencionaba que la norma en examen tenía que contemplar un equilibrio entre los derechos de los periodistas y las posibilidades de información de las empresas periodísticas. De esta forma, a nuestro parecer esta licencia se asienta en el motivo de permitir un acceso

48. Acerca de lo dicho, se debe tener presente que la doctrina nacional pone de relieve la importancia de que en el contrato de trabajo se determine la naturaleza de los servicios contratados, conforme dispone el artículo 10 numeral 3 del Código del Trabajo. Lo anterior, debido a que una descripción por medio de cláusulas abiertas o indeterminadas podría permitir al empleador variar arbitrariamente las condiciones en que el trabajador debe prestar sus servicios (Gamonal Contreras y Guidi, 2015).

49. En un similar sentido para el derecho español, Cabedo Serna (2011: 160-165). 
libre a la información a los ciudadanos a través de los distintos medios de prensa..$^{\circ}$

b) El profesional de la prensa independiente. El estatuto jurídico de los periodistas y colaboradores de la prensa independientes se encuentra en el artículo 24, letra c), numeral 2 de la Ley, que expresa:

Tratándose de producciones encomendadas por un medio de difusión a personas no sujetas a contrato de trabajo, aquel tendrá el derecho exclusivo para su publicación en la primera edición que se efectúe después de la entrega, a menos que hubiere sido encargada expresamente para una edición posterior. Transcurrido el plazo correspondiente, el autor podrá disponer libremente de ellas.

El primer apunte que debemos realizar es que las relaciones jurídicas entre el autor y la empresa periodística se reglamentarán conforme a un contrato de encargo de obra intelectual. Así, en su ejecución es posible apreciar dos fases, en la primera el autor tendrá que elaborar la obra según las instrucciones del comitente, y en la segunda, una vez entregada la creación, se llevará a cabo su publicación a través de un diario o revista. De esta suerte, el derecho exclusivo que la Ley concede a la empresa editora solo se adquiere a través de la entrega de la obra, pues antes de ese hecho le pertenecen al autor todos los derechos. ${ }^{51}$ Ahora bien, conviene destacar que esta facultad exclusiva de publicar otorgada al comitente es un elemento de la naturaleza de este contrato, de modo que no se requiere que se explicite en el mismo su transferencia, en los términos del artículo 73 de la Ley 17.336.

En segundo lugar, hacemos notar que el derecho de publicación que adquiere el comitente en este supuesto es notoriamente más endeble que aquel revisado a propósito de los trabajadores. Esto porque solo puede ser ejercido una vez, a menos que se pacte lo contrario. ${ }^{52} \mathrm{~A}$ su vez, la Ley le impone a la empresa comitente una carga para el ejercicio de este derecho de publicación, esta es, que temporalmente dicha facultad debe explotarse en la primera edición, conforme a la periodicidad del diario o revista pertinente. Pues en caso contrario, transcurrido dicho plazo, el autor podrá disponer libremente de la obra, a menos que se haya pactado que la creación haya sido encargada para una edición posterior. ${ }^{53}$ Esta regla, que tiene su fuente en el artículo 36 de la Ley francesa sobre Propiedad Literaria y Artística de 1957, da cuenta de que el autor conserva sus derechos para explotar su creación, a pesar del contrato celebrado, empero, tales facultades solo podrán ser llevadas a cabo sin competir deslealmente con

50. «Historia de la Ley 17.336», folio 210.

51. En similares términos para el derecho español, Serrano Fernández (2001: 110).

52. «Historia de la Ley 17.336», folio 210.

53. Cabe reprochar al legislador que haya determinado que el día inicial establecido para computar el término para publicar la obra encomendada sea contado desde la entrega y no desde su aprobación por el comitente, a diferencia del derecho común, conforme dispone el artículo 1.996, inciso 1 del Código Civil. 
el comitente, impedimento que desaparece una vez que haya difundido la obra o se haya vencido el plazo legal referido (Torres Lana, 1997: 845-849).

\section{La inadecuación al entorno digital del artículo 24, letra c) de la Ley 17.336}

Conforme a lo revisado, a nuestro parecer el artículo 24 letra c) de la Ley se muestra insuficiente para reglamentar las nuevas formas de explotación de las obras periodísticas en el ambiente digital. Ello, puesto que sus disposiciones se edifican sobre un concepto de publicación que resulta inadecuado para el entorno digital al requerir la presencia de ejemplares materiales del diario o revista que es distribuido. Asimismo, tampoco se regula qué derechos específicos tendrán los periodistas o colaboradores de prensa respecto de las formas de explotación de sus obras en las redes digitales. Finalmente, se omite toda referencia sobre la manera en que la empresa periodística puede utilizar las obras de sus dependientes o freelance en la economía de la innovación, en particular a través de nuevos formatos como las bases de datos o las ediciones electrónicas de sus diarios o revistas.

En términos generales, en principio se podría sostener que nuestra situación normativa es muy parecida a la exhibida en Estados Unidos a propósito de los profesionales independientes, o en Francia hasta antes de la reforma legal de 2009, debido a que todo nuevo uso que realice la empresa periodística sobre las obras de sus profesionales que no esté expresamente autorizado en el contrato respectivo se consideraría ilícito. Así, a modo de ejemplo, se podría estimar que el titular de periódico no podría digitalizar sus ediciones impresas y ponerlas a disposición de sus lectores en su sitio web. Esto, puesto que tales operaciones suponen disponer de los derechos de reproducción y comunicación pública, facultades cuyo ejercicio debe ser autorizado por el titular originario de los derechos, a menos que se cuente con una excepción legal al efecto. ${ }^{54}$ En el caso particular de nuestra Ley, consideramos que las mencionadas facultades patrimoniales - el derecho de reproducción establecido en el artículo 5, letra u, y el de derecho de comunicación pública descrito en el artículo 5, letra vse ven envueltas en la explotación digital de las obras de los autores, aunque con el matiz de que respecto del derecho de reproducción se dispone en el artículo 71 letra $o$ de la Ley 17.336 de una excepción sobre las copias temporales técnicas que tiene lugar con ocasión de la transmisión de los contenidos en redes.

A su vez, es necesario subrayar que el argumento de neutralidad de medios, esto es, que la explotación digital de una obra está cubierta por el derecho de publicación

54. Según Garrote, la transmisión digital de obra es una operación compleja, que implica reproducciones permanentes y efímeras en la memoria RAM del dispositivo del usuario, así como su puesta a disposición. De este modo, desde el plano teórico afirma tal autor que son varios los derechos patrimoniales exclusivos que entran en juego. Sobre estas ideas, véase Garrote Fernández-Díez (2003: 173-174). 
sobre la edición impresa, no ha sido acogido en algunas jurisdicciones. Las razones que se esgrimen son que las obras digitales, como es la edición en internet de un periódico, o su inclusión en bases de datos, tienen una naturaleza distinta, ya sea porque los contenidos son diversos a la versión impresa, $55 \mathrm{o} \mathrm{bien,} \mathrm{puesto} \mathrm{que} \mathrm{el} \mathrm{cambio} \mathrm{de}$ soporte entraña a su vez una mutación del tipo de obra protegible. ${ }^{56}$

\section{Posibles enfoques frente a la inadecuación de artículo 24, letra c) de la Ley a las nuevas formas de explotación digital}

Una primera orientación que podría seguirse para reglamentar adecuadamente el tratamiento de la utilización de las obras de los profesionales de la prensa en el campo digital es efectuar una reforma legislativa siguiendo el ejemplo francés. Por el contrario, a nuestro parecer es posible postular una segunda aproximación sobre esta materia, según la cual ciertas utilizaciones que realiza el empresario periodístico sobre las obras de sus trabajadores en el ámbito digital son legalmente admisibles, puesto que ha operado entre ambos sujetos una cesión tácita de derechos. Los argumentos de esta tesis son tanto de naturaleza funcional como dogmática, como tendremos ocasión de revisar.

Motivaciones de índole funcional que fundamentan un régimen de cesión tácita de derechos de los profesionales de la prensa a favor de los empleadores

Respecto de las consideraciones funcionales, se esgrime que el derecho de autor debe propender a una eficiente asignación de los recursos, de forma que deben ser concedidos a aquella parte de una relación jurídica que está en mejor posición de explotarlos a un bajo costo, que en este caso serían las empresas periodísticas, las que tendrían mayores capacidades financieras y tecnológicas para realizar comunicaciones informáticas masivas que los autores individuales (Hardy, 1988: 181).

En relación con lo anterior, se sostiene que una interpretación amplia que admita esta cesión tácita de derechos en internet no lesiona los intereses de los profesionales de la prensa, puesto que permite que sus obras sean accesibles a un mayor público, lo

55. En este punto, Rodríguez Tapia (2013: 55) afirma que las nuevas ediciones digitales de los diarios y revistas empezaron a tener contenidos distintos a la edición impresa, y brindan a los usuarios una interacción con el medio diversa al tradicional. De este modo, para este autor no es posible hablar de un simple cambio de formato de reproducción, sino que derechamente se está ante una nueva obra, la edición digital.

56. Acerca de lo dicho, la doctrina se ha visto perpleja para determinar la tipología de las páginas web, ya que junto con determinar que es un programa de computación (código fuente que permite su funcionamiento), también la presentación visual de la misma puede ser protegida como obra literaria, obra audiovisual o base de datos, según sea el elemento que predomine en ella (Garrote Fernández-Díez, 2003: 36-49). 
cual les puede reportar otros beneficios pecuniarios relevantes distintos de los royalties. ${ }^{57}$ Adicionalmente, se indica que la aplicación de una regla que requiere que todo nuevo uso del autor sea expresamente autorizado no considera los elevados costos de transacción que ello implica, puesto que supondrá que las partes de manera continua estén renegociando sus derechos (Rosenzweig, 1995: 921-924).

Por otro parte, se añade que estos costos de transacción aumentan exponencialmente debido a la fragmentación de numerosos titulares de derechos que integran un periódico o revista, lo que se conoce como la tragedia de los anticomunes (tragedy of the anticommons) (Parisi y Sevcenko, 2001: 328). Así, a modo de ejemplo, la empresa periodística debería negociar de manera individual con cada uno de sus autores para poder disponer de una versión digital de su diario o revista impresa, carga que es tan elevada que inhibe cualquier desarrollo tecnológico para distribuir información socialmente deseable Darling (2012: 503-505).

Finalmente, se señala que una regla que requiera de una autorización previa del profesional de la prensa para comunicar digitalmente su creación integrada en una obra colectiva, como es un periódico, no iría en beneficio del autor, sino por el contrario, al tratarse de obras periodísticas - por ejemplo, un reportaje o una fotografía- que muchas veces carecen de un valor comercial intrínseco, lo más probable es que ellas no sean explotadas individualmente, cuestión que difiere si ellas se incluyen dentro de una obra colectiva renombrada - como podría ser The New York Times-, que con su publicación digital permitirá que tales producciones se mantengan accesibles a nuevos lectores. ${ }^{58}$

\section{Motivaciones dogmáticas que otorgan soporte a un régimen de cesión tácita de derechos de los autores a favor de los titulares de los medios de prensa}

En cuanto a los argumentos dogmáticos para fundamentar esta orientación, estimamos relevante considerar como antecedente previo que esta cuestión no puede ser resuelta exclusivamente bajo las normas del derecho de autor. No se debe olvidar que en el caso trabajadores dependientes, la contraprestación que reciben a cambio del derecho que adquiere la editora empleadora para publicar sus obras es de naturaleza laboral, de ahí que debe tratarse esta materia teniendo a la vista ambos ordenamientos. A partir de lo dicho, estimamos que respecto de los autores dependientes es posible sostener que nuestro sistema legal admite la cesión tácita de los derechos de autor que le permitiría al empresario periodístico explotar digitalmente las obras de sus trabajadores con los debidos resguardos, como tendremos ocasión de revisar más adelante.

57. New York Times Co. con Tasini, 533 U.S. 521 (2001).

58. New York Times Co. con Tasini, 533 U.S. 521 (2001). 
Para fundamentar esta posición, en un principio revisaremos sistemas jurídicos comparados, que pertenecen a la familia del droit d’auteur, que admiten la cesión presunta de los derechos de los trabajadores a favor de su empleador respecto de las obras creadas en el marco de una relación laboral..$^{59}$

A continuación, demostraremos que un esquema de cesión tácita de derechos resulta acorde con los intereses tenidos a la vista al momento de la promulgación del artículo 24 letra c) de la Ley. A su vez, examinaremos qué es lo que ha dicho la dogmática laboral sobre la atribución al empleador de los frutos de la labor de su trabajador, en particular respecto de las creaciones del ingenio. ${ }^{60}$

\section{El derecho comparado de manera general admite la cesión tácita de derechos del trabajador a favor del empleador}

En cuanto al primer aspecto mencionado, Lucas-Schloetter, en un estudio sobre la creación asalariada y derecho de autor en los países de la familia del droit d’auteur, da cuenta que no es posible apreciar un único sistema de cesión de derechos de los autores a favor de sus empleadores. Distingue así algunas leyes que establecen que solo el autor es el titular de los derechos y, por tanto, debe haber una transferencia expresa del dependiente hacia su empleador para que pueda explotar la obra. Por su parte, otras legislaciones disponen de una transmisión de los derechos patrimoniales al empleador por la vía de presunciones. ${ }^{61}$ Finalmente, en un tercer grupo de países se reconoce una cesión tácita de dichas facultades por los autores dependientes al titular de la empresa (Lucas-Schloetter, 2005: 15-79).

59. Acerca de lo dicho, los profesores Guibault y Hugenholtz, en un estudio sobre la materia encargado por la Unión Europea sostienen: «Parece existir una tendencia creciente a nivel europeo a reconocer, bien por ley o judicialmente, la existencia de una presunción de propiedad a favor del empleador, cuando una obra es creada por un empleado en el desempeño de sus funciones o siguiendo las instrucciones por el empleador» (Guibault y Hugenholtz, 2002: 25).

60. La obra de referencia en esta materia es Valdés Alonso (2001).

61. Es ilustrativo de esta opción normativa la Ley de Propiedad Intelectual española, en cuyo artículo 51 se dispone: «Transmisión de los derechos del autor asalariado: 1) La transmisión al empresario de los derechos de explotación de la obra creada en virtud de una relación laboral se regirá por lo pactado en el contrato, debiendo este realizarse por escrito; 2) a falta de pacto escrito, se presumirá que los derechos de explotación han sido cedidos en exclusiva y con el alcance necesario para el ejercicio de la actividad habitual del empresario en el momento de la entrega de la obra realizada en virtud de dicha relación laboral; 3) en ningún caso podrá el empresario utilizar la obra o disponer de ella para un sentido o fines diferentes de los que se derivan de lo establecido en los dos apartados anteriores; 4) las demás disposiciones de esta Ley serán, en lo pertinente, de aplicación a estas transmisiones, siempre que así se derive de la finalidad y objeto del contrato; 5) la titularidad de los derechos sobre un programa de ordenador creado por un trabajador asalariado en el ejercicio de sus funciones o siguiendo las instrucciones de su empresario se regirá por lo previsto en el apartado 4 del artículo 97 de esta Ley». 
Dentro de este último colectivo de legislaciones se encuentra la italiana, la que se caracteriza - al igual que la chilena- por no tener una norma general que reglamente la cesión de los derechos de los trabajadores a favor de los empleadores. De esta suerte, por la influencia dogmática que tuvo la Ley italiana de 1941 con relación a nuestra Ley, nos parece que deber ser examinada como un elemento de confronte para tratar la cuestión de estudio en nuestro derecho. ${ }^{62}$

Un aspecto relevante de la legislación italiana es que solo de manera parcializada regula ciertas cesiones de los derechos de los trabajadores sobre sus creaciones a favor de los empleadores. A este respecto, en particular es destacable la reglamentación sobre las obras fotográficas, que tiene una evidente semejanza con la nuestra. ${ }^{63}$

Luego, frente a la ausencia de una regla general sobre la materia, la doctrina y la jurisprudencia han sostenido que la existencia de un contrato de trabajo tiene como efecto natural atribuir al empresario la titularidad de los derechos patrimoniales sobre las obras creadas por sus trabajadores (Gatti, 2005:3). Por consiguiente, los frutos que emanan de la actividad creadora de un autor al interior de una organización empresarial, y en el curso de su trabajo, se le asigna derivativamente a su empleador, pues ello obedece al propósito práctico del contrato de trabajo celebrado libremente entre las partes (Fabiani, 1990: 163). ${ }^{64}$

62. La influencia de Ley italiana de Derechos de Autor de 1941 como fuente material de la Ley 17.336 es evidente, según hemos acreditado a propósito de la reglamentación sobre la tutela de las obras de arte aplicada a la industria (Bernet Páez, 2014: 359-366). Asimismo, se debe destacar que se menciona la Ley italiana de 1941 expresamente como fuente en su historia fidedigna (folio 197).

63. Sobre lo expresado, el artículo 88 de la Ley italiana de derechos de autor de 1941, en lo que es pertinente, señala: «El derecho exclusivo de reproducción, difusión y distribución de la fotografía será del fotógrafo, con excepción a las disposiciones establecidas en la segunda sección del capítulo 6 del presente título, relativas al retrato y sin perjuicio de los derechos de autor sobre la obra de arte figurativa reproducida en la fotografía. Sin embargo, si la obra fotográfica se obtuvo en el curso y en la ejecución de un contrato de encargo o de trabajo, el derecho exclusivo le corresponde al comitente o al empleador, dentro de los límites del objeto y los fines del contrato». Adicionalmente, el artículo 89 de la referida Ley indica: «La cesión del negativo o de los medios negativos o análogos de reproducción de la fotografía incluirá, salvo acuerdo en contrario, la transferencia de los derechos previstos en el artículo anterior, siempre que dichos derechos sean del titular». Sobre las normas italianas precitadas, Valerio de Sanctis sostiene que se puede inferir la existencia de un principio general del derecho de autor conforme al cual dentro de los límites del objeto y de la finalidad del contrato debe entenderse cedidos al comitente o al empleador los derechos patrimoniales sobre la obra (De Sanctis, 1961: 412). Esta argumentación, a nuestro parecer puede ser utilizada de manera análoga en nuestro derecho, debido a la evidente semejanza del precitado artículo 89 de la Ley italiana con el del artículo 34 de la Ley 17.736, el cual prescribe: «Corresponde al fotógrafo el derecho exclusivo de reproducir, exponer, publicar y vender sus fotografías, a excepción de las realizadas en virtud de un contrato, caso en el cual dicho derecho corresponde al que ha encargado la obra, y sin perjuicio de lo que establece el número 1 de la letra c) del artículo 24. La cesión del negativo o del medio análogo de reducción de la fotografía, implica la cesión del derecho exclusivo reconocido en este artículo».

64. En esta línea, es relevante el estudio de Oppo (1996: 12-13) sobre la materia, que haciendo un 
De este modo, a falta de una cláusula particular de cesión de derechos, se infiere que el contrato de trabajo importa la transferencia tácita al empleador de los derechos de explotación de las obras creadas por los trabajadores que sean necesarios para el ejercicio de las actividades normales y habituales de dicha empresa (De Sanctis y Fabiani, 2007: 87). Por el contrario, no le serán cedidos al empresario los derechos de las obras realizadas apartadas del ámbito del contrato de trabajo, como aquellas efectuadas fuera del horario o alejadas de las labores usuales del autor dependiente (Cabedo Serna, 2011: 324).

En síntesis, en dicho sistema jurídico se estima que esta solución es ajustada a los intereses de empleadores y trabajadores, ya que respecto de los primeros se concluye que esta cesión tácita corresponde a la función económica y social de la relación laboral, en la cual el empleador hace suyo lo elaborado por su trabajador, sin que exista ninguna razón para excluir de tal regla a las obras intelectuales. Asimismo, a fin de cautelar a los trabajadores, se destaca que la cesión queda limitada a los derechos indispensables para dar cumplimiento a los objetivos perseguidos por las partes en la celebración del contrato (Fabiani, 1990: 162).

Por otro lado, en una similar situación normativa se encuentra el derecho alemán, con la peculiaridad de que en dicho ordenamiento, al seguirse una concepción monista del derecho de autor, no se contempla la cesión total o parcial de los derechos, sino solamente la concesión del uso de los mismos por su autor a favor de terceros (Dietz, 1983: 399).

Luego, en el caso de los trabajadores, la Ley de Derechos de Autor y conexos no dispone de manera expresa una presunción de licencia de las creaciones elaboradas por los dependientes a favor de sus empleadores. No obstante, a partir del párrafo 43 de la Ley, la doctrina de manera unánime interpreta que tal disposición consagra una regla según la cual el contrato de trabajo implica la transferencia al empleador de los derechos de uso sobre las obras de sus trabajadores (Lucas-Schloetter, 2005: 26). ${ }^{65}$ En este mismo sentido, la jurisprudencia ha dicho que los trabajadores tienen la obligación de otorgar a sus empleadores una licencia de uso de sus creaciones que sea suficientemente amplia para que los empresarios puedan llevar a cabo sus actividades comerciales usuales (Maseda Rodríguez, 2016: 255; Guibault y Hugenholtz, 2002: 7576; Klett, Sonntag y Wilske, 2008: 62).

contrapunto respecto de la titularidad de las invenciones creadas por los trabajadores en el marco de un vínculo laboral, en donde la ley sobre invenciones expresamente le otorga los derechos de explotación al empleador, asevera que tal solución debería también seguirse en el ámbito del derecho de autor, proponiendo como principio general que todo el resultado creativo de una actividad laboral que se inserta en una organización empresarial debe pertenecer al empleador.

65. El párrafo 43 de la ley dice: «Las disposiciones de esta subsección se aplicarán también cuando el autor haya creado la obra de conformidad con sus obligaciones en virtud de un contrato de trabajo o servicio, a menos que el contenido o la naturaleza de la relación de empleo o servicio establezca lo contrario». 
En este ámbito, creemos que es relevante volver sobre la posición normativa francesa acerca de una posible cesión tácita de derechos de los trabajadores a sus empleadores. Como hemos explicado previamente, el derecho galo tiene una postura estricta, puesto que requiere que toda concesión de facultades patrimoniales por el autor a un tercero sea consentida en forma expresa, y es indiferente de que dicho potencial cesionario sea el empleador (Lucas, Lucas y Lucas-Schloetter, 2012: 181).

Con todo, se debe apuntar que cierta dogmática, con apoyo en jurisprudencia que actualmente no es mayoritaria, ha esgrimido la admisión de la cesión implícita de derechos en el ámbito laboral (Maseda Rodríguez, 2016: 256). En este sentido, se sostiene que judicialmente es posible justificar una concesión tácita del trabajador a su empleador en la medida que el empresario utilice a su nombre la obra en cuestión, y que el dependiente no haya ejercido ningún reclamo en su contra. ${ }^{66}$

En este orden, la doctrina francesa autorizada ha criticado esta mirada restringida de la jurisprudencia (Lucas-Schloetter, 2005: 31). Ello se debe a que tampoco en dicho sistema se admite pactar en los contratos de trabajo una cláusula que permita de manera anticipada la cesión de las creaciones que el trabajador elabore durante el curso de su relación laboral (Ahner y Touati, 2010: 85). ${ }^{67}$ Lo anterior trae aparejado que ante el riesgo de una posible invalidación de este tipo de estipulación, se postule que los trabajadores de manera periódica deban transferir retroactivamente los derechos patrimoniales sobre las obras creadas en su labor, lo cual en el desarrollo de una actividad empresarial se vuelve impracticable (Lucas-Schloetter, 2005: 66).

Este escenario normativo de incerteza jurídica ha llevado a que se discuta en el Consejo Superior de la Propiedad Literaria y Artística de Francia una posible reforma legal que sugiere eliminar la prohibición de cesión global de derechos en sede laboral, al menos en el caso de los convenios colectivos. ${ }^{68}$

En resumen, de esta revisión de derecho comparado es posible distinguir que de manera general se admite la cesión tácita de los derechos del dependiente a favor del empleador, o bien, se autoriza a este último a utilizar las obras creadas por sus

66. Se debe mencionar que esta presunción de transferencia es de suyo frágil, puesto que solo puede ser invocada por el empresario en contra de terceros infractores - no contra el autor-, y puede ser derribada si se demuestra que el consentimiento del empleado fue obtenido por error, dolo o fuerza al momento de la celebración del contrato de trabajo (Guibault y Hugenholtz, 2002: 63-64).

67. Tal posición se asienta en el artículo en el artículo 131-1 del Código de Propiedad Intelectual, que prescribe que toda cesión global de obras futuras es nula.

68. Conseil Superieur de la Propriete Litteraire et Artistique, «Rapport d'activité 2001-2002 du CSPLA», Ministère de la Culture, 18 de abril de 2002, disponible en http://bit.ly/2Hn8PgY. Acerca de la expresión «convenio colectivo», se considera el siguiente concepto: «El convenio colectivo puede definirse como acuerdo escrito entre una representación de trabajadores y un empresario o una representación empresarial para la regulación de las condiciones de empleo y trabajo y la ordenación de las relaciones laborales» (Martín Valverde, Rodríguez-Sañudo Gutiérrez y García Murcia, 2016: 365). 
trabajadores en el curso normal de sus negocios, para lo cual es particularmente útil el examen al derecho italiano, en atención a la notoria similitud que tiene con el nuestro. En este sentido, se estima que la circunstancia de que una obra sea creada en el marco de una relación laboral naturalmente tiene incidencia en la posterior utilización de dichas producciones por el empresario, puesto que él es quien ha aportado todos los medios organizativos y materiales para que la misma llegue a la luz. Por el contrario, de seguirse un enfoque estricto como el expuesto en el derecho francés, no se entregarían soluciones a esta temática, sino al contrario, solo se incrementaría la inseguridad jurídica sobre la utilización de estas obras.

\section{La admisión de la cesión tácita de derechos es ajustada a los fines perseguidos} por el artículo 24, letra c), numeral 1, inciso 1 de la Ley

De acuerdo con lo examinado anteriormente, los objetivos buscados por el legislador al redactar el actual artículo 24, letra c), numeral 1 de la Ley fue cautelar los intereses tanto de la empresa periodística como de los autores dependientes. Respecto de la primera, se dispuso que tendría un derecho permanente para publicar las obras de sus dependientes en los diarios, periódicos o revistas en los cuales presten sus servicios, autores que solo recibirán como contraprestación su salario. En cuanto a los trabajadores, se les reconoce un derecho a una remuneración adicional si sus obras son publicadas en otros diarios o revistas distintos a los cuales prestan sus servicios, ya sea que pertenezcan o no a su empleador; asimismo, conservan sobre sus creaciones los demás derechos que la Ley les confiere.

De esta manera, en lo que dice relación con los autores dependientes no cabe duda de que sus empleadores pueden hacer uso de sus obras tantas veces lo estimen, a fin de que se incluyan en la publicación periódica donde prestan sus servicios. Esto con la única limitación de no realizar una explotación individual de tales producciones, ya que al respecto de ellas el autor ha mantenido sus derechos.

A partir de lo dicho, cabe preguntarse si la empresa periodística como titular de los derechos de utilización sobre la obra colectiva (periódico o revista) puede realizar actos de explotación digital. A nuestro parecer, como lo ha resuelto la jurisprudencia estadounidense - y que como veremos ha sido seguida en España-, consideramos que el empresario está autorizado para hacer ciertas utilizaciones electrónicas, en la medida en que las creaciones de los autores aparezcan formando parte de la obra colectiva editada originalmente en papel.

En otras palabras, si los textos, dibujos o fotografías de los dependientes son reproducidos por la empresa periodística por medio de una edición digital de la revista o periódico previamente impresa, en dicho supuesto pensamos que no habría una utilización no autorizada, ya que tales creaciones son mostradas de manera idéntica que la publicación escrita, pues se trataría solo de un cambio en el formato. Por el 
contrario, si las obras son explotadas de forma separada o distanciada del contexto en el cual fueron publicadas, esto es, no asociadas a la obra impresa, entonces se requeriría para tal aprovechamiento el consentimiento del autor.

La tesis planteada se ilustra en el caso La Vanguardia, decidido por la Audiencia Provincial de Barcelona, de 2006. ${ }^{69}$ Este litigio se inició por una demanda presentada por autores de fotografías, los cuales si bien habían cedido sus obras para ser incluidas en la edición en papel del diario La Vanguardia, sostenían que dicho medio infringía sus derechos al incorporarlas en el sitio web lavanguardia.es, en el cual no solo se reproducía el diario impreso, sino que además se incorporaban nuevos contenidos informativos y una bases de datos, circunstancias que permitían sostener que tal página web se trataba de una obra nueva y distinta de la obra colectiva original.

El Tribunal esgrimió dos motivos relevantes para rechazar la acción de los fotógrafos que tenían la calidad de dependientes del periódico. El primer argumento indicaba que a falta de pacto expreso sobre los alcances de la cesión de derechos, se debía presumir que se había transferido por el dependiente al empresario en régimen de exclusiva los derechos patrimoniales sobre las obras creadas en el marco de la relación laboral. Luego, tal cesión presunta no era absoluta, ya que estaba limitada a aquellas facultades necesarias para el ejercicio habitual del empresario al momento de la entrega de la creación. Así, en lo que nos interesa, la Audiencia Provincial de Barcelona sostuvo que a la fecha de la entrega de las fotografías (2001 y 2002) era habitual que los empresarios del sector prensa explotaran sus publicaciones mediante ediciones en formato digital, por lo cual se debía considerar lícita la explotación de las obras en el mismo.

En cuanto al segundo fundamento invocado, la Audiencia señaló que en el sitio web de la demandada no se realizaba una explotación individual de las fotografías, puesto que ellas no se incorporaban a las actualizaciones, sino que eran reproducidas en su contexto originario ilustrando los contenidos de la edición impresa. En este mismo sentido, se alude que las ediciones digitales estaban almacenadas en el sitio como una hemeroteca que no cumplía con el concepto legal de bases de datos, al ser solo un reflejo de los derechos que le correspondían a la empresa como titular de dichas obras colectivas.

A nuestro parecer resulta admisible en nuestro derecho la posición dogmática expresada en el asunto La Vanguardia, puesto que cautela de manera balanceada los dos intereses en juego que persigue tutelar el artículo 24, letra c), numeral 1, inciso 1 de la Ley, y que son los del empresario periodístico y de los trabajadores.

En cuanto al primero, la Ley a fin de asegurar que el titular del medio de prensa utilice económicamente las obras de sus dependientes, le otorga la facultad para pu-

69. Sentencia de la Audiencia Provincial de Barcelona, 10 de marzo de 2006, ponente: Luis Garrido Espa. 
blicarlas en la medida que se inserten en su obra colectiva. Luego, resulta evidente que si el legislador atribuyó tal facultad al empleador para que este obtenga réditos financieros de su publicación periódica, entonces de modo inherente también se le tendría que permitir difundir la misma a través de internet, en la medida que no haga uso individual de las creaciones de sus trabajadores..$^{\circ}$

Respecto a los segundos, la Ley introduce dos elementos para su tutela, a saber, un derecho a una remuneración adicional a favor del trabajador si sus obras son divulgadas en una publicación distinta a la que prestan sus servicios, y la conservación de sus derechos para explotar sus creaciones de manera individual. Dicho esto, debemos concluir que la difusión de la edición en internet de un diario o revista impresa no afecta a ninguno de los elementos revisados, pues tal actividad no constituye una publicación en un medio distinto al cual ejecuta sus servicios como dependiente, sino que se trata de la misma obra colectiva exhibida en otro formato, de ahí que no devengue una remuneración adicional. Acto seguido, la publicación electrónica en idénticos términos que la obra colectiva en papel no es una explotación individual de las producciones de los trabajadores, sino que, como han sostenido las jurisprudencias estadounidense y española, se trata simplemente de la misma obra expresada en otro medio o continente.

\section{La cesión de derechos es una obligación consustancial al contrato de trabajo}

Desde una perspectiva propia del derecho laboral, cabe determinar si en virtud de un contrato de trabajo el autor dependiente solo se obliga con su empleador a la prestación de una actividad intelectual, o bien, también le confiere la facultad de utilizar o valerse de los resultados del trabajo conforme al objeto propio de su negocio. Para resolver tal inquietud, es necesario tener en consideración una característica propia del contrato de trabajo. Ella consiste en el carácter oneroso de esta convención, ${ }^{71}$ de modo que «la causa de la obligación salarial radica en la prestación contenida» (Fernández Prol, 2005: 43-44).

Por esto, un sector de la doctrina sostiene que el contrato de trabajo celebrado por un autor no solo le impone la obligación de desarrollar una actividad creativa, sino que también atribuye al empleador los derechos de utilización o explotación de la obra (Valdés Alonso, 2001: 96-97). En efecto, como afirma Hurtado González (2001: 467), los derechos de explotación sobre la obra son también un fruto del trabajo, por lo que el contrato de trabajo de autor atribuye la titularidad de dichos derechos al empresario. Situados en el caso de una empresa periodística que contrató a un pe-

70. En un mismo sentido para el derecho español, Yagüe Blanco (2017: 73-74).

71. En cuanto al carácter conmutativo del contrato de trabajo, véase Gamonal Contreras y Guidi (2015: 7), Thayer Arteaga y Novoa Fuenzalida (2007: 107). 
riodista redactor de noticias, el resultado esperado de dicha prestación de servicios consistirá en un artículo noticioso, toda vez que es la clase de producto que pone a disposición de sus lectores..$^{72}$ Precisamente, todo empresario contrata los servicios de trabajadores «con el fin de producir bienes o rendir prestaciones a terceros, o mejor decir al público» (Diéguez Cuervo, 2001: 840).

Este criterio se fundamenta en un elemento del contrato de trabajo como es la «ajenidad», que junto con la dependencia y subordinación constituye una de las notas esenciales del contrato de trabajo. ${ }^{73}$ Consiste básicamente en que los frutos que produce un trabajador con la prestación de sus servicios revierten directamente en favor del empleador, quien obtiene un beneficio por ellos. Surge así la exigencia de compensar al trabajador, y de ahí la necesidad de una remuneración para el que trabaja (Alonso Olea y Casas Baamonde, 2006: 55-56). De esta manera, como afirma Diéguez Cuervo (1995: 23), la remunerabilidad del trabajo es una consecuencia de su ajenidad.

En conexión con lo anterior, en el ámbito del derecho de autor, se sostiene que la remuneración que recibirá el trabajador de su empleador retribuye tanto la actividad creativa como la cesión de los derechos de explotación sobre las obras producidas en el marco de la relación laboral (Cabedo Serna, 2011: 472). Esto se debe, como se ha dicho previamente, a que el empresario no obtendría ninguna utilidad de la mera ejecución de los servicios por su dependiente, o bien, con la entrega de lo creado. Por el contrario, solo recogería los frutos de lo ejecutado por sus trabajadores si se le permite utilizar económicamente las obras creadas por ellos durante la vigencia del contrato laboral (Valdés Alonso, 2001: 129).

Con todo, corresponde advertir que en materia de derecho de autor la nota de ajenidad se encuentra morigerada, por cuanto la cesión de dicho resultado no tiene por qué abarcar la integridad de los derechos de propiedad intelectual. Recuérdese que es característica general de la propiedad intelectual la pluralidad y complejidad

72. La actividad del trabajador puede ir dirigida a conseguir una prestación o resultado determinado, pero debe tratarse de uno «esperado», empleando la diligencia debida. De esta forma, el trabajador se compromete a prestar una actividad (actuación diligente) considerada en sí misma y tendente a conseguir un fin, aunque el logro efectivo no sea debido; no promete el resultado, sino la adopción de las medidas adecuadas, normalmente conducentes a su obtención. Se da, así, una conexión entre actividad y resultado en la relación de trabajo. De ahí, por lo demás, la existencia de remuneraciones que precisamente se fijan conforme al logro de resultados, como puede ser una "pieza, obra o medida» (véase el artículo 44 del Código del Trabajo).

73. Sobre el reconocimiento del elemento de la ajenidad en la doctrina nacional, véase Gamonal Contreras (1998: 15 y ss.). Sobre el reconocimiento del elemento de la ajenidad en los tribunales del trabajo, véase Segundo Juzgado de Letras del Trabajo, 3 de diciembre de 2009, RIT-11-2009; Segundo Juzgado de Letras del Trabajo, 14 de febrero de 2011, RIT-O-3365-2010; Primer Juzgado de Letras de Santiago, 8 de octubre de 2010, RIT-O-1929-2010. 
de facultades de carácter personal y patrimonial que se atribuye al autor. Y dentro de esas facultades algunas son inalienables o no susceptibles de cesión a terceros, como es el caso de aquellas que integran el llamado derecho moral, dentro de las que se encuentra la de exigir el reconocimiento de la condición de autor de la obra (Altés Tarrega, 2011: 8). Así las cosas, en este ámbito la ajenidad reduce el concepto de fruto, y lo circunscribe principalmente a la utilidad patrimonial del mismo (Soler Masota y Luque Parra, 1999: 609). Por este motivo, Altés Tarrega afirma que la diferencia del autor dependiente de otros trabajadores es que, por el hecho de ser creador, goza de unos derechos sobre el resultado de su trabajo, en especial aquellos de naturaleza moral (Altés Tarrega, 2011: 8).

En síntesis, podemos concluir que en el contrato de trabajo de un autor, como lo es un profesional de la prensa, el objeto de dicho vínculo tiende a la obtención de un resultado, el cual se identifica con la atribución al empleador de los derechos de utilización de las obras creadas por su trabajador (Soler Masota y Luque Parra, 1999: 614; Valdés Alonso, 2001: 94).

Este criterio ha sido ratificado por la sentencia de la Corte de Apelaciones de Santiago, del 24 de agosto de 2015, en la cual se discutía si un periodista dependiente de una agencia de noticias tendría derecho a una indemnización como consecuencia de ciertas utilizaciones de sus obras realizadas por su exempleadora, las que consideraba el demandante como ilícitas, puesto que no se incluían expresamente en el contrato que vinculaba a las partes. Así, la Corte como fundamento para rechazar dicha acción afirmó:

Que, consiguientemente, el reproche del actor o el hecho ilícito que acusa no ha podido ser tal si se le ha hecho consistir en la distribución o comercialización de los artículos noticiosos creados por el mismo, ya que con su contrato de trabajo, en calidad de redactor - hecho no discutido - surgió para la empleadora, ahora demandada, el derecho de distribuir por sí misma las obras de su trabajador, ahora demandante. En otros términos, la actividad esencial de la demandada, consistente en distribución de material periodístico a sus clientes, le ha conferido el derecho a comercializar por sí misma las obras del actor, lo que ha hecho ajustándose a la normativa vigente, esto es, a cambio de la remuneración que le ha pagado mensualmente al actor, en su calidad de trabajador y conforme los términos de tal convención. ${ }^{74}$

De esta manera, al considerar como dice la Corte que el contrato de trabajo por sí mismo tiene la virtud de ceder los derechos del trabajador a favor de su empleador, entonces el paso siguiente será determinar cuáles son las facultades patrimoniales específicas sobre las obras creadas por los dependientes que son cedidas tácitamente al empresario en virtud del contrato de trabajo. Sobre ello, la doctrina señala que en

74. Sentencia de la Corte de Apelaciones de Santiago, 24 de agosto de 2016, rol 3010-2015, capítulo 12. 
tal indagación se deberá atender a las siguientes circunstancias fácticas, estas son: i) el giro o tráfico profesional del trabajador, y ii) el sector de la actividad económica, en donde se desarrolla el empleador. ${ }^{75}$

En cuanto al primer aspecto de hecho mencionado, se deberá estar a lo dicho en el respectivo contrato de trabajo, en particular a la descripción de la naturaleza de las funciones del trabajador (artículo 10, numeral 3 del Código del Trabajo). Como se sabe, esta descripción es una de las menciones mínimas del contrato de trabajo, de manera que la determinación de la prestación que llevará a cabo el trabajador servirá para precisar el resultado esperable de la misma. En cuanto a la segunda cuestión fáctica referida, se deberá indagar cuál es la actividad habitual del empleador, para lo cual no solo se deberán considerar las modalidades de explotación actual que desarrolla, sino también las que sean previsibles de realizar en el futuro. ${ }^{76}$

De esta suerte, es posible concluir que si un autor es contratado para desempeñar labores de periodista o colaborador de prensa en una empresa periodística, se deberá comprender que a su empleador, aunque nada diga el contrato, se le concederán en virtud del mismo los derechos de explotación de las obras creadas por sus dependientes que sean necesarias para la ejecución del giro habitual de la empresa, comprendidas dentro de esta última expresión — por la simple observación del mercado de la prensa- el desarrollo de ediciones tanto impresas como digitales.

\section{Recapitulación}

Como hemos revisado, frente a la inadecuación del artículo 24 letra c) de la Ley al entorno digital es posible escoger dos orientaciones. La primera, de lega ferenda, impone realizar una reforma legislativa que incorpore la explotación de las obras en el marco de la economía digital. La segunda, de lege lata, da cuenta que existen argumentos funcionales y dogmáticos que permitirán sostener que el empresario estaría autorizado para utilizar las obras periodísticas en el ámbito electrónico, en particular

75. Esta opinión es seguida en el derecho español por Yagüe Blanco (2017: 30).

76. Sobre este segundo elemento que determina el ámbito de la cesión de derechos sobre una obra asalariada, la Audiencia Provincial de Barcelona, en el asunto La Vanguardia, señala: «De otro lado, el interés protegible del autor asalariado debe ponderarse con el equilibrio necesario para no menoscabar la innovación e iniciativa empresarial, evitando que el empresario tan solo pueda obtener del autor asalariado los derechos sobre obras habituales, pero no sobre nuevos tipos de obras o nuevas modalidades de explotación que, proyectadas para un futuro próximo, habitualmente no venía explotando. De ahí que la doctrina especializada abogue por el entendimiento del parámetro de la habitualidad con referencia no tanto a la trayectoria de la empresa en relación con cierta modalidad de explotación, sino a la trayectoria y presencia del empresario en el sector de mercado de que se trate, comprendiendo la actividad habitual relevante a estos efectos aquella que, por operar en ese sector, es previsible o haya sido seriamente proyectada, siempre que exista cierto grado de concreción próxima al momento de entrega de la obra». 
debido al influjo que tiene el derecho laboral en esta materia. A nuestro parecer, este último enfoque tiene asidero en nuestro derecho, por lo que se requiere a continuación dar cuenta de una serie de reglas particulares aplicables a los profesionales de la prensa en el entorno digital.

\section{Una propuesta sobre los derechos de los profesionales de la prensa escrita en el ámbito digital}

Si concordamos con la premisa de que ciertas utilizaciones que realiza el empresario respecto de las obras de los profesionales de la prensa en el ámbito digital son legalmente admisibles, cabe determinar como último escalón de nuestra investigación dos cuestiones relevantes. La primera es, a falta de pacto expreso entre las partes, a qué profesionales de la prensa escrita - trabajadores o independientes- es posible postular una cesión tácita de derechos a favor del empresario que le permita explotar digitalmente tales creaciones. Aclarado lo anterior, una segunda interrogante a resolver es la extensión de la utilización de las obras periodísticas por el empresario, lo cual implica determinar los modos legítimos de explotación de las producciones en el ámbito digital.

\section{La utilización digital de las obras de los profesionales de la prensa}

En cuanto a la inicial incógnita planteada, según se ha enunciado, proponemos como primera tesis que el empresario periodístico, a falta de una cesión expresa por el autor, solo podrá utilizar en el campo digital aquellas obras creadas por sus trabajadores para la edición escrita, puesto que únicamente en el ámbito laboral es posible sugerir una cesión tácita de derechos. Por el contrario, en cuanto a los periodistas independientes, necesariamente se debe contar con un acuerdo que faculte de manera explícita al empresario a realizar un uso electrónico de aquellas obras que originalmente fueron editadas en papel, puesto que la existencia de un encargo previo para confeccionar un texto o una fotografía no es suficiente por sí mismo para que se presuman cedidos los derechos a favor del comitente. ${ }^{77}$

En cuanto a esta diferencia de tratamiento, la misma se fundamenta esencialmente en razones sistemáticas, como también en consideraciones propias del derecho laboral. En cuanto a las primeras, basta recordar que el artículo 24, letra c) de la Ley distingue de manera nítida la situación jurídica de los autores trabajadores con los independientes. Así, en cuanto al profesional dependiente, en atención a que su obra es creada en el marco de una relación laboral, no dispone de la misma con autonomía, al concederse por la ley el derecho de publicación de tal producción a su empleador. Por

77. Del mismo modo en el derecho español, Rodríguez Tapia (1997b: 841). 
el contrario, el periodista independiente, una vez transcurrido el plazo de la primera edición de la publicación respectiva, se le faculta para utilizar su creación de manera libre.

Dicho contraste revela que solo respecto del trabajador es posible estimar una posible cesión tácita de derechos, mientras que con relación al independiente, la Ley le concede un amplio margen de libertad en el uso de su obra, por lo cual el empresario comitente, en ausencia de pacto expreso, solo podrá utilizar la creación encargada respecto de la llamada «primera impresión».

Como complemento de lo anterior, se destaca que la posición del empresario respecto de una obra es muy distinta si es empleador o comitente del creador. Es así como, en el primer supuesto, el autor actúa bajo una relación de dependencia o subordinación y su obra es confeccionada con los elementos técnicos y humanos puestos a su disposición por su empleador. En cambio, el empresario comitente solo le encarga una obra a un autor, quien si bien debe seguir en parte las instrucciones dadas, elabora su creación con sus propios medios (Antequera Parilli, 2002: 5).

De esta forma, el vínculo estrecho entre la actividad del empresario con la labor creativa del autor trabajador justifica que se le atribuya al primero, sin necesidad de pacto, los derechos para explotar la obra conforme a las modalidades vigentes al tiempo de la prestación de los servicios. ${ }^{78}$ Por el contrario, en aquel supuesto que la obra es creada sin el soporte organizacional de una empresa, no es admisible una cesión tácita, por lo que debe seguirse una transferencia expresa de derechos, lo cual no es más que una aplicación de la regla del artículo 1.996 del Código Civil, norma que impone que únicamente se entiende cumplido el encargo de una obra cuando es aprobada por el comitente. ${ }^{79}$

Acerca de los fundamentos dogmáticos de la cesión tácita de derechos del autor trabajador a favor del empleador, estimamos que puede ser ilustrativa la sentencia de la Corte de Casación italiana, del 1 de julio de 2004, en especial por la similitud que exhibe la ley italiana con la nuestra. ${ }^{80}$

Este litigio se inició por una demanda presentada por el periodista Giuseppe Bruno en contra de su empleadora Radio Televisión Italiana, en la cual la acusaba de infringir sus derechos de autor al utilizar su publicación digital Mondo Italia on line, obra cuya explotación no estaba prevista en el contrato de trabajo respectivo. La Corte, para motivar el rechazo de la acción deducida, inicia su razonamiento indicando que la ley italiana no contiene un precepto que de manera general ordene que los derechos de autor del dependiente serán asignados al empleador. Dicho esto, esgrime que de manera aislada la ley contempla diversas hipótesis que otorgan tales faculta-

78. En un similar sentido, Schuster Vergara (2009: 383).

79. Una semejante opinión para el derecho italiano, De Sanctis y Fabiani (2007: 88).

80. Corte de Casación de Italia, sesión de trabajo, sentencia del 1 de julio de 2004, número 12.089. 
des al empresario, supuestos como programas de computación, bases de datos, obras colectivas, publicaciones periódicas y las obras cinematográficas. ${ }^{81}$ De este modo, la Corte infiere a partir de dichas disposiciones que el ordenamiento italiano consagra como principio general que el empresario adquiere directamente el resultado de la labor de su trabajador, sin necesidad de un acto de transferencia expresa, por ser un efecto natural del contrato de trabajo.

Luego, la Corte, al volver sobre el asunto planteado, da por probado que la obra periodística invocada por el demandante, si bien es de su autoría, fue creada en el entorno logístico de la organización empresarial, inclusive con ayuda de otros colaboradores del medio. De esta manera, al tratarse de un resultado natural y previsible del contrato de trabajo celebrado, ello implica de manera indefectible que los derechos de explotación económica de dicha revista digital le corresponden a la demandada.

En otras palabras, para este tribunal el intérprete deberá indagar si existe una relación de causalidad entre la actividad del trabajador y la creación realizada, de forma que si la obra es una consecuencia evidente del contrato de trabajo su explotación cederá a favor del empleador. En un sentido contrario, si la producción es fruto de un esfuerzo creativo desarrollado fuera del ámbito laboral, y sin el uso de herramientas que le pertenezcan al empleador, entonces el dependiente mantendrá en su poder todos los derechos sobre las obras.

A modo de recapitulación, nuestra primera propuesta es que, en ausencia de un pacto expreso, respecto de las obras periodísticas creadas inicialmente para una edición en papel el empresario de la prensa solo podrá explotar digitalmente las que han sido elaboradas por sus trabajadores. De este modo, todas aquellas obras creadas por periodistas o colaboradores de la prensa independientes podrán ser utilizadas por el titular de un medio de prensa en un entorno digital solo si cuenta con una cesión o autorización expresa de su autor. Dicho esto, nos abocaremos a precisar los alcances de la explotación legítima que puede realizar el empresario respecto de las obras de sus trabajadores en el campo electrónico.

\section{Modos legítimos de explotación digital de las obras de los trabajadores}

De acuerdo con lo que hemos postulado hasta ahora, el contrato de trabajo conlleva una cesión tácita de los derechos que ostenta el autor trabajador sobre sus obras a favor a su empleador, opción normativa que es seguida en el derecho comparado. So-

81. La Ley 17.336 mantiene un esquema normativo semejante al de la ley italiana, puesto que si bien no contiene una norma general atributiva de derechos a favor del empleador o comitente, dispone de reglas específicas para ciertas obras, que curiosamente son las mismas que la italiana, como programas de computación (artículo 8), bases de datos y compilaciones (artículo 24, letra b), obras colectivas (artículo 5, letra c), publicaciones periódicas (artículo 24, letra c) y obras cinematográficas (artículo 29). 
bre esto, es particularmente interesante para nuestro entorno lo dicho por la doctrina italiana, que ha llegado a tal conclusión a partir de disposiciones normativas muy similares a las contenidas en nuestra ley.

Dado lo expuesto, cabe indagar de qué manera específicamente tiene lugar dicha cesión tácita en el ámbito de las publicaciones periódicas, y en particular su explotación digital. En otras palabras, corresponde fijar qué facultades en concreto se le asignan al empresario periodístico respecto de las creaciones elaboradas por sus trabajadores en relación con las nuevas tecnologías.

A fin de responder tal inquietud, el primer parámetro que debe ser considerado es que el empleador solo podrá disponer de aquellas obras que hayan sido creadas por su dependiente con ocasión del contrato de trabajo, para lo cual es evidente en la determinación de este factor la descripción de la naturaleza de las funciones del trabajador contenida en el contrato de trabajo. En este sentido, siguiendo a Valdés Alonso (2001: 226), la actividad contratada servirá como un título previo que autorice la cesión entre trabajador y empresario, de forma que una desconexión radical entre la actividad contratada y la obra creada dificultará seriamente la posibilidad de cesión, a pesar de estar inmensos en una relación laboral. ${ }^{82}$

En segundo término, una vez que hemos determinado que la obra periodística tiene por causa el vínculo laboral, y por ello se produce una cesión tácita de derechos del trabajador a su empleador, debemos luego delimitar qué facultades patrimoniales en concreto sobre dicha creación quedan comprendidas con ocasión de la referida transferencia. En este punto, en ausencia de una cláusula contractual que regule la materia, sostenemos que se entenderán cedidas al empleador aquellas facultades sobre las obras que sean necesarias según la finalidad del contrato. ${ }^{83}$

Luego, en sede de creación periodística asalariada, resulta evidente que el fin práctico perseguido por las partes en el contrato de trabajo es que a cambio de una remuneración pagada, el empresario periodístico pueda explotar económicamente las obras creadas por sus dependientes conforme a su giro, y en especial según los usos

82. En un similar sentido, Rodríguez Tapia (1997b: 840 ) sostiene que debe tratarse de obras creadas en el marco de una relación laboral siguiendo las instrucciones del empleador, o ejecutadas en el cumplimiento de las funciones que le han sido asignadas en el contrato respectivo. De ahí que debe existir concordancia entre la creación con el puesto que desempeña el trabajador en concreto.

83. En la doctrina italiana, Oppo (1996: 34). En España, Pérez Pérez (1998: 281-282). Este canon interpretativo también se encuentra recogido en nuestra ley, en materia de licencias, al disponer su artículo 20, inciso final lo siguiente: «A la persona autorizada no le serán reconocidos derechos mayores que aquellos que figuen en la autorización, salvo los inherentes a la misma según su naturaleza». Así, según esta regla de interpretación contractual, al licenciatario no se le considerarán más derechos que los expresamente indicados en la autorización, con la salvedad de los que por su naturaleza se consideran incluidos en ella, por lo que conservan aquellos derechos necesarios para cumplir con el fin del contrato, incluso las facultades no expresamente descritas. 
corrientes del sector de la prensa. En este último punto, Yagüe Blanco (2017: 73-74) sostiene que la actividad habitual de un medio de prensa escrita se vincula principalmente con los derechos patrimoniales de reproducción de las obras cedidas en un soporte tangible como es el papel y su posterior distribución al público. Sin embargo, indica que con el desarrollo de las nuevas tecnologías los medios de prensa son hoy empresas multimedia, por lo cual la actividad habitual de estas compañías hoy se identifica también con formas de comunicación digital. Por esto es que se entienda cedida por los trabajadores a su empleador la facultad de puesta a disposición al público de sus creaciones por procedimientos inalámbricos, de lo cual son ejemplo las ediciones electrónicas de los periódicos.

\section{Límites que afectan al empleador en la explotación digital de las obras de sus trabajadores}

El desarrollo de esta segunda proposición no sería completo sin mencionar a qué límites debe someterse el empleador al momento de utilizar las obras periodísticas de sus trabajadores en el ámbito virtual, los cuales se desarrollarán en las siguientes líneas.

\section{El empleador no puede explotar individualmente las obras de sus trabajadores}

El primero se relaciona con la naturaleza jurídica de la obra de que es titular. Acerca de ello, se debe recordar que el periódico o revista es considerado por la ley como una obra colectiva, respecto de la cual el empresario como coordinador no adquiere el derecho para explotar individualmente los aportes que le son suministrados por los autores, sean o no sus trabajadores (Jiménez Martínez, 2005: 58). ${ }^{84}$

En este orden, siguiendo lo dicho por la Corte Suprema de Estados Unidos en New York Times con Tasini, si el empresario explota los aportes de sus trabajadores de manera distanciada de la obra impresa, como puede ser a través de una base de datos que permite el acceso separado de los textos o fotografías, requerirá de una autorización expresa de los autores, lo cual además se alejaría de la finalidad práctica tenida a la vista por las partes al momento de celebrar el contrato. ${ }^{85}$

\footnotetext{
84. Sin perjuicio de lo dicho, se debe mencionar según esta misma autora que los aportantes de una obra colectiva, en particular respecto de una publicación periódica, no podrían explotar individualmente sus creaciones si con ello causan un perjuicio para la obtención de un aprovechamiento económico de la obra colectiva, puesto que de lo contrario competirían deslealmente (Jiménez Martínez, 2005: 59). En términos más categóricos respecto del mismo ordenamiento, Soler Masota y Luque Parra (1999: 631), sostienen que el trabajador que incumpla este deber de lealtad arraigado en la buena fue puede ser objeto de un despido procedente, junto con el reclamo por los daños sufridos por el empleador.

85. La autora Cámara Aguilá (2010: 37), a fin de clarificar el conflictivo asunto de determinar en qué
} 
Sin embargo, al igual que lo dicho en el caso La Vanguardia, estimamos que una versión digital de una publicación periódica idéntica a la impresa, que es puesta a disposición al público a través de internet, no constituye una explotación individual de los aportes efectuados por los autores, debido a que dicha replica solo es un cambio de formato que no altera la sustancia de la obra colectiva, lo cual es además consistente con lo dicho por la jurisprudencia estadounidense en los litigios Faulkner y Greenberg. En esta línea, los archivos digitales de ediciones anteriores que se contienen en las páginas web de diarios o revistas solo sustituyen las hemerotecas disponibles en bibliotecas, y que, al estar ordenadas por un criterio cronológico, no reciben amparo como compilación o bases de datos; de ahí que tampoco puedan ser explotados comercialmente de manera autónoma. ${ }^{86}$

\section{El empleador no puede utilizar las obras de sus trabajadores en usos alejados de su giro habitual}

Un segundo límite que debe respetar el empleador en la utilización de las obras de sus trabajadores dice relación con aquellos usos ajenos a su giro o que no resulten habituales al empresario al momento de la celebración del contrato. Acerca de este límite, en términos generales se señala que la actividad usual u ordinaria de una empresa no se restringe a lo expresado en su objeto social, sino que se debe atender particularmente a las funciones productivas actuales de dicha organización económica (Valdés Alonso, 2001: 231-237), o bien, las que pueda previsiblemente ejecutar en el futuro (Rodríguez Tapia, 1997b: 841).

Luego, en el ámbito de la prensa, se deberá considerar como habitual no solo aquella actividad que es propia de la industria editorial impresa, como es la reproducción y distribución de ejemplares tangibles, sino que además, la que es previsible por las prácticas en el sector a la fecha de la suscripción del contrato respectivo, como son en la actualidad todas las modalidades de explotación multimedia, destacando que si en las mismas el empresario se sirve de terceros para su gestión, tal ulterior cesión o licencia no requerirá de una autorización expresa del trabajador (Soler Masota y Luque Parra, 1999: 621).

supuestos un empresario periodístico explota individualmente una obra aportada por un profesional de la prensa, nos ofrece como ejemplo aquella circunstancia en que la editora de un periódico cede a un tercero los derechos de explotación de una obra fotográfica realizada por un fotógrafo dependiente para hacer un cartel publicitario anunciando un producto dietético, el cual no tiene relación alguna con el medio de prensa.

86. Las bases de datos en nuestra ley (artículo 3 numeral 16) solo son protegidas si por razones de la selección o disposición de contenidos, constituyen una creación intelectual. De esta manera, existe consenso en que carecen de originalidad, y por lo tanto de protección, las compilaciones que disponen sus datos conforme a criterios lógicos o habituales, como la ordenación alfabética o cronológica (Minero Alejandre, 2013: 205). 


\section{El empleador no está facultado para aprovecharse de las obras de sus trabajadores} por medio de modalidades de explotación no conocidas al tiempo de la celebración del contrato

Finalmente, un tercer límite que debe observar el empleador en esta materia y que se encuentra muy vinculado con los anteriores, dice relación a que no podrá explotar las obras de sus trabajadores a través de modalidades de utilización desconocidas a la firma del contrato. En este sentido, al no pactarse en el contrato de trabajo qué derechos en concreto serán objeto de cesión, en caso alguno se podría admitir como cedidos modos de explotación que no eran conocidos a la época de la celebración del contrato (Hillig, 1977: 126).

Esta propuesta, que es coincidente con el canon hermenéutico de la finalidad del contrato, es particularmente recogida en el derecho alemán bajo la noción de Zweckübertragungsgrundsatz, ${ }^{87}$ para lo cual es relevante conocer la jurisprudencia germana dictada a propósito de ella. ${ }^{88}$ Se esgrime así que esta regla tiene la virtud de adaptarse a los nuevos tiempos, toda vez que los tribunales estimarán como conocido o no un nuevo uso si el mismo es técnicamente accesible al sector y es comercialmente explotable de forma separada a los métodos convencionales (Klett, Sonntag y Wilske, 2008: 65). A modo de ejemplo, se ha dictaminado que al año 1968 no era conocido el aprovechamiento económico de las obras cinematográficas a través de cintas de video, ${ }^{89} \mathrm{o}$ que al año 1999 la comercialización de filmes a través del DVD

87. Este término puede ser libremente traducido como «principio de transferencia de derechos según la finalidad». Aplicado al derecho de autor, es utilizado como una regla interpretativa conforme a la cual no se transfieren ni otorgan más derechos de los estrictamente necesarios para lograr el propósito del contrato celebrado, y que se encontraría contemplada en párrafo 31.5 de la Ley de Derechos de Autor alemana. En un similar sentido, Ruipérez de Azcárate (2010: 91) define Zweckübertragunstheorie como «teoría de la cesión conforme a la finalidad».

88. La doctrina sostiene que esta regla de prohibición de los usos desconocidos por el cesionario tiene su origen en pronunciamientos judiciales del Tribunal del Imperio Alemán de principios del siglo XX, para lo cual es particularmente relevante la decisión Das Musikantenmädel, de 1927, en la cual se le impidió al editor de la opereta del mismo nombre la explotación posterior como obra fílmica, a pesar que se le habían cedido todos los derechos sobre dicha creación (Darling, 2012: 492). Con posterioridad, esta misma regla se recogió en el párrafo 31.4 de la Ley de derechos de autor alemana, derogada con la reforma de 2007. Por su parte, Serrano Fernández (2012: 22) afirma que esta prescripción se orienta a proteger a los autores a fin de obtener réditos económicos sobre sus obras que no pudieran apreciar al momento de concertar la cesión de sus derechos. En el derecho francés se contempla que toda cesión de derechos de explotación mediante formas no previsibles al tiempo del contrato debe ser expresa (artículo 39 de la Ley de 1957, actual artículo L 131-6 del Código de Propiedad Intelectual), y del mismo modo en el derecho español se dispone que la transmisión de los derechos de explotación no alcanza a las modalidades de utilización o medios de difusión inexistentes o desconocidos al tiempo de la cesión (artículo 43.4 de la Ley de Propiedad Intelectual).

89. Tribunal Federal de Justicia de Alemania, 11 de octubre de 1990, I ZR 59/98. Con posterioridad, 
no constituía un uso nuevo, distinto al arriendo o venta de películas por medio de técnicas comunes en el mercado. ${ }^{90}$

Luego, en el ámbito de las publicaciones periódicas, resulta particularmente interesante la sentencia pronunciada por el Tribunal Federal Supremo en el caso Spiegel $C D-R O M$, de $2001 .^{91}$ Este litigio se inició por una demanda presentada por una asociación de fotógrafos freelance en contra de la revista Der Spiegel, por la cual acusaban a dicha publicación de realizar un uso no consentido de sus fotografías a través de la comercialización, a partir de la primavera de 1993, de una edición digital de tal medio de comunicación a través de un CD-ROM que contenía todos los volúmenes del año calendario. De esta manera, el asunto controvertido se centraba en determinar si esta forma de comercialización era un nuevo uso, y por ello no cubierto por el propósito del contrato de licencia celebrado por la revista y los fotógrafos, o bien, como indicaba la demandada, la venta de estos soportes era conocida al año 1989 cuando se suscribieron los convenios respectivos.

El Tribunal acogió la demanda presentada esgrimiendo que la distribución de la revista a través de este soporte digital no estaba cubierto por la licencia suscrita entre las partes. En este sentido, sostuvo que esta forma de edición tiene la potencialidad de abrir un nuevo e independiente mercado, distinto de las ediciones anuales en papel o en microfilm. Adicionalmente, el Tribunal destacó que la mera digitalización no era un nuevo uso, y que lo relevante en tal calificación son los efectos económicos derivados de esta diversa forma de comercialización de la publicación.

De esta manera, siguiendo lo expuesto por la jurisprudencia germana, se deberá indagar respecto del autor trabajador, si a la data de la suscripción de su contrato de trabajo con el empresario periodístico eran conocidas las modalidades de explotación digital de las publicaciones periódicas. Por consiguiente, a modo de ejemplo, si el contrato de trabajo fue suscrito en la década de 1970, resulta del todo inverosímil que el trabajador haya cedido tácitamente sus derechos para una ulterior utilización digital, por lo que en ese supuesto necesariamente se debe obtener su consentimiento para estos nuevos usos. Por el contrario, si el vínculo laboral ha nacido en la presente década, se deberá entender que las habituales formas de explotación digital — por ejemplo, edición electrónica o sitios web de la publicación - son del todo conocidas para cualquier profesional de la prensa, de ahí que su uso por su empleador será considerado lícito.

En síntesis, nuestra segunda propuesta consiste en que empresario periodístico,

por sentencia del Tribunal Federal de Justicia de Alemania, 26 de enero de 1995, I ZR 63/93, se estimó que la explotación de obras cinematográficas por medio de cintas caseras no era un uso desconocido al año 1971.

90. Tribunal Federal de Justicia de Alemania, 19 de mayo de 2005, I ZR 285/02.

91. Tribunal Federal de Justicia de Alemania, 5 de julio de 2001, I ZR 311/98. 
aun en ausencia de un pacto especifico, está habilitado para utilizar las obras de sus trabajadores a través de las modalidades de explotación digital, como lo son las ediciones digitales de los periódicos o revistas en los sitios web, puesto que ello obedece a la finalidad perseguida en el contrato de trabajo. No obstante, el empresario en el uso de tales creaciones tiene restricciones o límites, estos son, no podrá utilizar las mismas sin el consentimiento del autor de manera distanciada o diversa como aparece en la obra impresa; tampoco podrá ocupar las obras para fines distintos a su giro o alejadas de su actividad habitual, o que escapen a los usos conocidos al momento del inicio de la relación laboral.

\section{Recapitulación}

Como parte final de nuestra investigación hemos presentado dos propuestas que inciden en los derechos de autor de los profesionales de la prensa escrita en el ámbito de las nuevas tecnológicas. La primera de ellas es que, en ausencia de un pacto expreso, respecto de las obras periodísticas creadas inicialmente para una edición en papel el empresario de la prensa solo podrá explotar digitalmente las que han sido elaboradas por sus trabajadores, no admitiéndose en este ámbito una cesión tácita de derechos del profesional independiente a favor del empresario comitente. A continuación, nuestra segunda propuesta consiste en que si bien el titular del medio de prensa, como empleador, estará autorizado para utilizar digitalmente las obras de sus trabajadores, puesto que ello es inherente a la finalidad del contrato de trabajo, tal explotación estará sujeta a ciertos límites, como que las creaciones no podrán ser usadas distanciadas del giro habitual del empresario periodístico o respecto a formas desconocidas al momento de la suscripción del contrato respectivo.

\section{Conclusiones}

El propósito de esta investigación era determinar qué derechos de autor disponen los profesionales de la prensa escrita en Chile, tanto dependientes como independientes, respecto de sus obras creadas inicialmente para un medio impreso, las cuales posteriormente son explotadas a través de nuevos formatos digitales, como las ediciones en línea o las bases de datos. Así, de acuerdo al examen efectuado al artículo 24, letra c) de la Ley 17.336, podemos concluir que tal disposición se muestra insuficiente para reglamentar estas nuevas formas de explotación de las obras periodísticas, puesto que se cimenta en conceptos que se han visto superados por la innovación tecnológica, como el de publicación, el cual de acuerdo al texto de la Ley implica la reproducción y posterior distribución de ejemplares tangibles al público, lo que resulta a todas luces alejado de las actuales modalidades de comercialización de las publicaciones periódicas. 
A pesar de la ausencia de norma expresa que resuelva esta cuestión, estimamos que es posible considerar que ciertas utilizaciones que realiza el empresario periodístico sobre las obras de sus trabajadores en el entorno digital son legalmente admisibles, puesto que ha operado entre ambos una cesión tácita de derechos. Esta conclusión se asienta en comprender que el asunto planteado debe ser resuelto teniendo a la vista de manera conjunta los ordenamientos implicados, a saber, el derecho de autor y el derecho laboral. Por el contrario, respecto de las obras creadas por periodistas o colaboradores de la prensa freelance, las mismas solo podrán ser utilizadas por el titular de un medio de prensa en un ambiente digital si cuenta con una cesión o autorización expresa del autor.

En cuanto a las facultades que se le otorgan al empleador respecto de las creaciones periodísticas de sus trabajadores en el entorno digital, se debe apuntar como regla general que el empresario solo podrá utilizar las obras que tengan como causa el contrato laboral, por lo que quedan fuera de su potestad las obras que hayan sido concebidas por sus trabajadores distanciadas de la actividad contratada.

Del mismo modo, salvo pacto en contrario, al empresario no le estará permitido explotar de manera separada los aportes individuales de sus dependientes, como también le estará vedado usar las obras creadas por sus trabajadores en negocios alejados del giro periodístico o mediante la utilización de formas de explotación desconocidas al tiempo de la celebración del contrato de trabajo.

Finalmente, haciendo presente que este estudio se ha centrado de manera preferente en los profesionales de la prensa escrita, estimamos que las argumentaciones expresadas para justificar una cesión tácita de derechos de los trabajadores a favor de sus empleadores pueden servir como un primer paso dogmático para construir una teoría general sobre la transferencia de los derechos de autor en el marco de una relación laboral, con independencia del sector económico en que ella se presente.

\section{Referencias}

Ahner, Francis y Jean-Jacques Touati (2010). Inventions et créations des salariés: Du Code du Travail au Code de la Propiété Intellectuale. París: Lamy.

Alonso Olea, Manuel y María Emilia Casas Baamonde (2006). Derecho del Trabajo. Madrid: Civitas.

Altés Tarrega, Juan Antonio (2011). «El contrato de trabajo del autor asalariado: Supuestos de aplicación del artículo 51 de la Ley de Propiedad Intelectual». Relaciones Laborales, 1: 401-423.

Antequera Parilli, Ricardo (2002). «Taller: Primera sesión: 2) Autoría y titularidad: a) De las obras creadas por encargo y/o relación laboral». IV Congreso Iberoamericano sobre Derecho de Autor y Derechos Conexos: La Propiedad Intelectual, un Canal para el Desarrollo. Ciudad de Panamá: Organización Mundial 
de la Propiedad Intelectual, Ministerio de Educación de la República de Panamá. Disponible en http://bit.ly/2JxXUWU.

Ayer, Thomas (2009). «Protecting the little guy: Greenberg v. National Geographic Society, 533 F.ed 1244 (11th Cir. 2008), and $\$ 201$ (c) of the Copyright Act». Temple Journal of Science \& Environmental Law, 28: 153-184.

Berdaguer Mosca, Javier (2010). Obra colectiva y derecho de autor. Madrid: La Ley. BERNET PÁEZ, Manuel (2014). La presentación comercial en el derecho de la competencia desleal. Evolución en el derecho comparado y su protección en Chile. Santiago: Legal Publishing.

Cabedo Serna, Llanos (2011). El derecho de remuneración del autor. Madrid: Dykinson.

CÁmara Aguilá, Pilar (2010). «La obra colectiva: ¿Solución o problema?». Revista de Propiedad Intelectual, 35: 13-52.

Carbajo Cascón, Fernando (2002). Publicaciones electrónicas y propiedad intelectual. Madrid: Colex.

D'Agostino, Giuseppina (2000). "Copyright treatment of freelance work in the digital era». Santa Clara Computer \& High Technology Law Journal, 19 (1): 37-110. Disponible en http://bit.ly/2Hpf7fW.

DALlaL, Thomas (2007). «Faulkner v. National Geographic Enterprises, Inc.: Driving a truck through the eye of a needle». Texas Intellectual Property Law Journal, 15: 63-90.

DARLING, Kate (2012). «Contracting about the future: Copyright and New Media». Northwestern Journal of Technology and Intellectual Property, 10 (7): 485-530. Disponible en http://bit.ly/2sKvwqg.

Deriux, Emmanuel (2010). «La presse: Le droit d'auteur des jornalistes. Incidences de la loi du 12 juin 2009». En Créations et investions de salariés. Rompre avec les schémas reçus. París: Litec.

De Sanctis, Vittorio (1961). Diritto di autore: Disciplina del diritto di autore e dei diritto connessi. Milán: Giuffrè.

De Sanctis, Vittorio y Mario Fabiani (2007). I contratti di diritto di autore. Milán: Giuffrè.

Diéguez Cuervo, Gonzalo (1995). Lecciones de derecho del trabajo. Madrid: Marcial Pons.

-. (2001). «Empresarios con personalidad plural (la secuela última de un concepto equívoco)». Civitas, 108: 837-851.

DiETz, Adolf (1983). El derecho de autor en la Comunidad Europea. Madrid: Ministerio de Cultura.

Doscotch, Matthew y Steven McAuley (2001). «New York Times Co. v. Tasini: Striking a balance between the rights of a freelance author in their individual works 
and the rights of a publisher in its collective works». University of Illinois Journal of Law, Technology \& Policy, 1: 225-231. Disponible en http://bit.ly/2xOr5Af.

Evangelio Llorca, Raquel (2013). "Comentario a los artículos 3 y 4». En Rodrigo Bercovitz Rodríguez-Cano (coordinador), Comentarios al Convenio de Berna para la Protección de las Obras Literarias y Artísticas. Madrid: Tecnos.

Fabiani, Mario (1990). «Sezione terza: Acquisto e vicende traslative ed estintive del diritto di autore». En Pietro Rescigno (director), Trattato di diritto privato. Turín: Utet.

Fernández Prol, Francisca (2005). El salario es especie. Valencia: Tirant Lo Blanch.

FIsk, Catherine (2003). «Authors at work: The origins of the work-for-hire doctrine». Yale Journal of Law \& The Humanities, 15 (1): 1-70. Disponible en http://bit. ly/2sNtkhL.

Gamonal Contreras, Sergio (1998). Introducción al derecho del trabajo. Santiago: Conosur.

-. (2014). Fundamentos de derecho laboral. Santiago: Thomson Reuters.

Gamonal Contreras, Sergio y Caterina Guidi (2015). Manual del contrato de trabajo. Santiago: Legal Publishing.

Garrote Fernández-Díez, Ignacio (2003). El derecho de autor en internet. Los Tratados de la OMPI de 1996 y la incorporación al Derecho Español de la Directiva 2001/29/CE. Granada: Comares.

Gatti, Serafino (2005). «Opera dell'ingegno su commissione e disciplina del diritto d'autore». Rivista del Diritto Commerciale, 1: 1-40.

Gómez Abelleira, Francisco Javier (1999). Litigios entre empresario y trabajador sobre patentes, secretos industriales y derechos de autor en los Estados Unidos. Santiago de Compostela: Universidad de Coruña.

GraY, Naomi Jane (2003). «Comment: Analyzing the publisher's section 201 (c) privilege in the wake of New York Times v. Tasini». Case Western Law Review, 53 (3): 647-652. Disponible en http://bit.ly/2Hql4JR.

Guibault, Lucie y Bernt Hugenholtz (2002). Study on the conditions applicable to contracts relating to intellectual property in the European Union. Amsterdam: Institute for Information Law.

HaRdy, I. T. (1988). «An economic understanding of copyright law's work-made-forhire doctrine». Columbia-VLA Journal of Law \& The Arts, 12: 181-228. Disponible en http://bit.ly/2HpRyUB.

Hillig, Hans-Peter (1977). «Contractual freedom in German copyright law». En Herman Cohen Jeroham (editor), Copyright contracts. Amsterdam: Universidad de Amsterdam.

Hurtado González, Luis (2001). «Contrato de trabajo y derechos de propiedad intelectual de los autores». Relaciones Laborales, 1: 457-478. 
JimÉnez MarTínez, María Victoria (2005). El autor y las publicaciones periódicas: El régimen jurídico específico del texto refundido de la Ley de Propiedad Intelectual. Alcalá de Henares: Universidad de Alcalá.

Jollymore, Nicholas (1990). «Ancillary uses of collective works». Communications and the Law, 12: 21-47.

KLETT, Alexander, Matthias Sonntag y Stephan Wilske (2008). Intellectual property in Germany: Protection, enforcement and dispute resolution. Múnich: Beck.

KoRANSKY, Jason (2009). «Magazine publishers exhale: Exploiting collective works after Greenberg». The John Marshall Review of Intellectual Property Law, 8: 161-183. Disponible en http://bit.ly/2Hpmx2M.

LÉGER, Jean Marie (2011). «La cession légale des droit d’auteur des journalistes: Considérations practiques sur les contributeurs et œvres víses par le texte». Droit de Limmatériel, 77: 2.569-2.573.

Lucas, André, Henri-Jacques Lucas y Agnès Lucas-Schloetter (2012). Traité de la propieté littérarie et artistique. París: Lexis Nexis.

Lucas-Schloetter, Agnès (2005). «La creation salariee et le droit contractuel d’auteur. Etude de droit compare». Revista de Propiedad Intelectual, 25: 21-79.

Martín Valverde, Antonio, Fermín Rodríguez-Sañudo Gutiérrez y Joaquín García Murcia (2016). Derecho del trabajo. Madrid: Tecnos.

Maseda Rodríguez, Javier (2016). La ley aplicable a la titularidad original de los derechos de propiedad intelectual sobre las obras creadas en el marco de una relación laboral. Santiago de Compostela: Universidad de Santiago de Compostela.

Meitus, Robert (2000). «Interpreting the Copyright Act's section 201(c) revision privilege with respect to electronic media». Federal Communications Law Journal, 52 (3): 749-776. Disponible en http://bit.ly/2kU8Hww.

Merges, Robert, Peter Menell y Mark Lemley (2010). Intellectual property in the new technological age. Nueva York: Aspen Publishers.

Minero Alejandre, Gemma (2013). «Comentario al artículo 2.5». En Rodrigo Bercovitz Rodríguez-Cano (coordinador), Comentarios al Convenio de Berna para la Protección de las Obras Literarias y Artísticas. Madrid: Tecnos.

MTima, Lateef (2004). «Tasini and its progeny: The new exclusive right or fair use on the electronic publishing frontier». Fordham Intellectual Property Media \& Entertainment, 14 (2): 369-461. Disponible en http://bit.ly/2kYkoEl.

Navas Navarro, Susana (2015). «El periódico: ¿Obra colectiva?». Actas de Derecho Industrial y Derecho de Autor, 35: 387-396.

NordemanN, Jan Berd (2006). «The US “work-for-hire” doctrine before German courts: Rejection and reception». Journal Copyright Society of the USA, 53: 605-638.

Oppo, Giorgio (1996). «Creazione intellectuale, creazione Industriale e diritto di utilizzazione economica». Rivista di Diritto Civile, 1: 1-45. 
O'Rourke, Maureen (2003). «Bargaining in the shadow of Copyright Law after Tasini». Case Western Reserve Law Review, 53: 605-638.

PAssa, Jerôme (1999). «The protection of copyright of the internet under French Law». En Frédéric Pollaud-Dulian (editor), The internet and authors' righs. Londres: Sweet \& Maxwell.

Parisi, Francesco y Catherine Sevcenko (2001). «Lessons from the anticommons: The economics of New York Times Co. v. Tasini». Kentucky Law Journal, 90: 295328. DOI: $10.2139 / \mathrm{ssrn} .286458$.

PÉrez PÉRez, Manuel (1998). «Derecho de autor y relación de trabajo». Relaciones Laborales, 2: 268-292.

Rodríguez Tapia, José Miguel (1997a). «Comentario al artículo 8 de la Ley de Propiedad Intelectual». En José Miguel Rodríguez Tapia y Fernando Bondía Román (autores), Comentarios a la Ley de Propiedad Intelectual. Madrid: Civitas.

-. (1997b) «Comentario al artículo 51 de la Ley de Propiedad Intelectual». En Rodrigo Bercovitz Rodríguez-Cano (coordinador), Comentarios a la Ley de Propiedad Intelectual. Madrid: Tecnos.

-. (2013). «Periodistas asalariados y colaboradores de prensa». En Miguel Ángel Encabo Vera (coordinador), Periodismo y derecho de autor. Madrid: Reus.

Rogel VIDE, Carlos (2013). «Periodismo y derecho de autor: Una aproximación histórica». En Miguel Ángel Encabo Vera (coordinador), Periodismo y derecho de autor. Madrid: Reus.

Rosenzweig, Sidney (1995). «Don't put my article online! Extending copyright's new-use doctrine to the electronic publishing media and beyond». University of Pennsylvania Law Review, 143: 921-924.

Ruipérez de Azcárate, Clara (2010). Diccionario de propiedad intelectual e industrial: Alemán-español-alemán. Madrid: Reus.

Saiz García, Concepción (200o). Objeto y sujeto del derecho de autor. Valencia: Tirant Lo Blanch.

Schechter, Roger y John Thomas (2003). Intellectual property: The law of copyrights, patents and trademarks. St. Paul: Thomson West.

Schuster Vergara, Santiago (1997). «El derecho de autor y los derechos conexos en el mundo digital». Tercer Congreso Iberoamericano sobre derecho de autor $\mathrm{y}$ los derechos conexos: 110 años de protección internacional del Derecho de Autor: Berna, 1996, Ginebra, 1996. Montevideo: Organización Mundial de la Propiedad Intelectual, Ministerio de Educación y Cultura del Uruguay, Instituto Interamericano de Derecho de Autor.

-. (2009). «Derechos de autor en las relaciones laborales y su vínculo con el Tratado de Libre Comercio entre Chile y Estados Unidos». En Rodrigo Velasco Santelices y Marcos Morales Andrade (coordinadores), Homenaje a Arturo Alessandri Besa: Estudios de derecho y propiedad intelectual. Santiago: Jurídica de Chile. 
Segal Ayers, Irene (200o). «International Copyright Law and the electronic media rights of authors and publishers». Hastings Commercial Entertainment Law Journal, 22 (1): 29-63. Disponible en http://bit.ly/2sIOCNo.

Serrano Fernández, María (2001). Contratos en torno a la edición. Madrid: Reus.

-. (2012). «Régimen jurídico de transmisión de los derechos de autor en el ordenamiento español y alemán». Indret, 4: 1-35. DOI: 10.2139/ssrn.2185330.

Siprut, Joseph (2008). «Greenberg v. National Geographic Society: The Eleventh Circuit clarifies the privileged revision doctrine of the Copyright Act». Hasting Communications and Entertainment Law Journal, 30 (1): 521-532. Disponible en http://bit.ly/2yoYNmz.

Soler Masota, Paz y Manuel Luque Parra (1999). «Relación laboral y propiedad intelectual: el caso de los reporteros gráficos». Relaciones Laborales, 2: 593-633.

STEWART, Stephen (1989). International copyright and neighbouring rights. Londres: Butterworths.

Terry, Amy (2004). «Tasini aftermath: The consequences of the freelancers' victory». Depaul Journal Art \& Entertainment Law, 14 (2): 231-256. Disponible en http://bit. ly/2xO9YPf.

Thayer Arteaga, William y Patricio Novoa Fuenzalida (2007). Manual de derecho del trabajo. Santiago: Jurídica de Chile.

Torres Lana, José Ángel (1997). «Comentario al artículo 52 de la Ley de Propiedad Intelectual». En Rodrigo Bercovitz Rodríguez-Cano (coordinador), Comentarios a la Ley de Propiedad Intelectual. Madrid: Tecnos.

Uribe Corzo, María Carolina (2007). «El derecho de autor en las obras por encargo y en el marco de una relación laboral». Revista de Propiedad Inmaterial, 10-11: 4570. Disponible en http://bit.ly/2xRSe5t.

VAldÉs Alonso, Alberto (2001). Propiedad intelectual y relación de trabajo. La transmisión de los derechos de propiedad intelectual a través del contrato de trabajo. Madrid: Civitas.

VARET, Vicent (2000). «Comentario a sentencia de Corte de Apelación de Lyon, de 9 de diciembre de 1999». Revue Internationale du Droit d'Auteur, 184: 361-371.

WAlKer ECHenique, Elisa, (2014). Manual de propiedad intelectual. Santiago: Legal Publishing.

Yagüe Blanco, Sergio (2017). Cláusulas de cesión de derechos de propiedad intelectual en los convenios colectivos laborales: Estudio de negoción colectiva. Valencia: Tirant Lo blanch.

\section{Agradecimientos}

La redacción de este artículo ha contado con la ayuda del Fondo Nacional de Ciencia y Tecnología de la República de Chile, en el marco del Proyecto Fondecyt Regular 
1170894, titulado «Propiedad intelectual y derecho del trabajo: Régimen jurídico de las creaciones realizadas por el trabajador», en el cual los autores tienen la calidad de investigador responsable y coinvestigador, respectivamente.

\section{Sobre los autores}

Manuel Antonio Bernet Páez es abogado. Doctor en Derecho por la Universidad de los Andes. Profesor de Derecho Comercial de la Universidad de los Andes. Su correo electrónico es mbernet@uandes.cl.

Alfredo Sierra Herrero es abogado. Doctor en Derecho por la Universidad de Santiago de Compostela, España. Profesor de Derecho Laboral de la Universidad de los Andes, Chile. Su correo electrónico es asierra@uandes.cl. 


\title{
REVISTA CHILENA DE DERECHO Y TECNOLOGÍA
}

La Revista de Chilena de Derecho y Tecnología es una publicación académica semestral del Centro de Estudios en Derecho Informático de la Facultad de Derecho de la Universidad de Chile, que tiene por objeto difundir en la comunidad jurídica los elementos necesarios para analizar y comprender los alcances y efectos que el desarrollo tecnológico y cultural han producido en la sociedad, especialmente su impacto en la ciencia jurídica.

\author{
EDITOR GENERAL \\ Daniel Álvarez Valenzuela \\ (dalvarez@derecho.uchile.cl) \\ SITIO WEB \\ rchdt.uchile.cl \\ CORREO ELECTRÓNICO \\ rchdt@derecho.uchile.cl \\ LICENCIA DE ESTE ARTÍ́CULO \\ Creative Commons Atribución Compartir Igual 4.0 Internacional
}

\begin{abstract}
y
La edición de textos, el diseño editorial

y la conversión a formatos electrónicos de este artículo

estuvieron a cargo de Tipográfica

(www.tipografica.cl).
\end{abstract}

